\title{
SUPPORTING INDIVIDUALS WITH FETAL ALCOHOL SPECTRUM DISORDERS: A SUMMARY OF EFFECTIVE PRACTICES
}

\author{
JENNIFER L. RIGGIE AND TINGTING XU
}

Florida State University

\section{Author Note}

Jennifer Riggie, School of Teacher Education, Florida State University; Tingting Xu, School of Teacher Education, Florida State University.

Correspondence concerning this article should be addressed to Jennifer Riggie, School of Teacher Education, Florida State University, 1114 West Call Street, Stone Building, G107 Tallahassee, FL 32306. E-mail: jlr09c@my.fsu.edu

\begin{abstract}
Fetal alcohol spectrum disorder (FASD) is a lifelong condition that significantly affects the individual's learning, development, behavior, family, and quality of life. Diagnosing children with this condition and providing effective supports is challenging for professionals because little intervention research has been performed with the population. This is frustrating for caregivers who often take an active role in their child's life to ensure that needs are met. This article summarizes quantitative and qualitative studies that have targeted learning and behavioral interventions that aim to support children with FASD and their families. Research suggests that practices accommodating children's neurocognitive and neurobehavioral deficits are likely to produce positive outcomes. Interventions that include the family are also promising in their effectiveness. Extra attention needs to focus on early intervention for infants and toddlers and interventions that can promote the self-determination of adults with FASD. Additional directions for future research are provided along with policy and practice implications.
\end{abstract}

Fetal Alcohol Spectrum Disorders (FASD) is an umbrella term for a group of conditions impacting individuals whose mothers consumed alcohol during their pregnancy (Center for Disabilities, 2008; Center for Disease 
Control and Prevention [CDCP], 2011). Prevalence estimates for children with FASD could be a much as 2-5\% in the United States (May et al., 2009). The main clinical diagnoses associated with FASD in the US are Fetal Alcohol Syndrome (FAS), Alcohol-Related Birth Defects (ARBD), and AlcoholRelated Neurodevelopmental Disorder (ARND) (CDCP, 2011). Fetal Alcohol Effects (FAE) was a term previously used but replaced; other terms like Partial Fetal Alcohol Syndrome (pFAS) are still used to describe conditions on the spectrum (CDCP, 2011). Individuals with FASD can have physical, neurological, and/or developmental challenges that vary greatly from one person to another (CDCP, 2011), depending on the amount of consumption, the duration of use, and the patterns of alcohol exposure (Day et al., 2013; Streissguth, 1997).

Diagnosing children with one of the FASD conditions is difficult because currently there are only assessments for FAS and not the other diagnostic categories (CDCP, 2010b). A diagnosis for one of the other conditions is based upon the extent of characteristics in the following four key areas: facial abnormalities, decreased pre/post-natal growth, impairments in the central nervous system, and prenatal alcohol exposure. The National Task Force on FAS and FAE recommends steps be taken to allow for early diagnosis, diagnosis criteria for all FASD conditions, and the addition of FASD as a disability under federal guidelines (Olson et al, 2009a).

Results from the 2010 National Survey on Drug Use and Health indicate that over $10 \%$ of pregnant women between the ages of 15 and 44 reported current alcohol usage (Substance Abuse and Mental Health Services Administration, 2011). Further, over 3\% of pregnant women reported binge drinking and $1 \%$ heavy drinking. Although these percentages are drastically lower than women who are the same age and not pregnant (54\%,24\%, and $5 \%$ respectively), the CDCP (2010a) report that, "There is no known safe amount of alcohol to drink while pregnant" (para. 1). The effects of prenatal alcohol exposure for the estimated 40,000 children born each year in the United States could be prevented if women refrained from alcohol consumption during their pregnancy (CDCP, 2010a; Lupton, Burd, \& Harwood, 2004).

Per child with FAS, it is estimated that 16,800 dollars are spent each year on medical expenditures; this is nine times greater than the average cost per year of children without this condition (Amendah, Grosse, \& Bertrand, 2011). There is no cure for FASD and the challenges associated with this developmental disability persist throughout the individual's lifespan. Current data on the lifetime cost for an individual with FASD are unavailable; data from about a decade ago indicate that the costs associated with care for all 
individuals with FAS in the United States exceeds four billion dollars each year (Lupton, Burd, \& Harwood, 2004).

About half of all individuals with FASD need support across at least two developmental areas (Dumaret, Cousin, \& Titran, 2010). Individual and family characteristics and risk factors tend to result in children with FASD having disrupted school experiences, failing a grade of school, receiving special education services, and/or needing separate school placements for individuals with severe medical or learning needs (Dumaret et al., 2010). These challenges in school are often outcomes of deficits in cognition, information processing, and challenging behaviors (Kodituwakku, 2007; Riley \& McGee, 2005). Behavioral and emotional challenges do not stop at school, however. About half of those with FASD have problems with the law and/or regular inappropriate sexual behaviors, while a third experience drug or alcohol problems (Streissguth et al., 2004).

Even with these alarming data, little attention has been given to the diagnosis and educational interventions for this population (Coles \& Black, 2006). Three research summaries were conducted in the past decade describing the effects of prenatal alcohol exposure on children (Dixon, Kurtz, \& Chin, 2008; Kalberg \& Buckley, 2007; Kodituwakku, 2007). An additional six studies focused on methods educators (Caprara, Nash, Greenbaum, Rovet, \& Koren, 2007; Green, 2007; Kodituwakku, 2010; Peadon, RhysJones, Bower, \& Elliott, 2009), caregivers (Rowbottom, Merali, \& Pei, 2010) and nurses (Caley, Kramer, \& Robinson, 2005) could take to meet the needs of children with FASD. Four researchers focused their recommendations on the classroom, specifically, assessment (Caprara et al., 2007; Kalberg \& Buckley, 2007), learning interventions (Green, 2007), and behavioral interventions (Kodituwakku, 2010). One review targeted each of the following for its recommendations: medicine (Peadon et al., 2009), positive caregiving experiences (Rowbottom et al., 2010), and prevention of FASD (Caley et al., 2005).

Although researchers have come to a general agreement on the physical and neurological challenges associated with this population (Mattson et al., 2013), minimal studies have researched the effects of interventions for individuals with FASD, or other supports to enhance the quality of life for the children and their families. Many problems remain to be examined. The primary purpose of this article is to summarize the research targeting individuals with FASD and their families to gain a holistic view of practices that show promise of effectiveness with this population. Secondary purposes of this article are to present implications for professionals in the field and future directions for researchers and policymakers. 


\section{METHODS}

Quantitative and qualitative studies were included in the research synthesis if they targeted educational, behavioral, or social interventions for individuals with FASD and/or their families. Studies were identified using PsycINFO and ERIC databases without date restrictions using the identifiers of fetal alcohol spectrum disorder OR fetal alcohol syndrome AND instruction OR intervention. A total of 391 studies were found with PsycINFO and 64 with ERIC. Of these studies, 21 met the inclusion criteria. Over half of these studies used experimental or quasi-experimental methods (Bertrand, 2009; Coles, Kable, \& Taddeo, 2009; Engle, 2008; Kable, Coles, \& Taddeo, 2007; Keil, Paley, Frankel, \& O’Connor, 2010; Kerns, Macsween, Wekken, \& Gruppuso, 2010; Loomes, Rasmussen, Pei, Manji, \& Andrew, 2008; O'Connor et al., 2006; O'Connor et al., 2012; Roebuck-Spencer \& Mattson, 2004; Vernescu, 2007; Wells, Chasnoff, Schmidt, Telford, \& Schwartz, 2012). Qualitative studies used purposeful sampling (Carpenter, 2011) and included a case study (Duquette, Stodel, Fullarton, \& Hagglund, 2006) and pilot study (Grant et al., 2004). Other qualitative studies were explored using ethnography (Edmunds $\&$ Crichton, 2008), grounded theory (McGregor, 2009), and contextual comparison (Ryan \& Ferguson, 2006). The remaining studies used either reversal (Kurtz, Chin, Rush, \& Dixon, 2008) or multiple baseline (Padgett, Strickland, \& Coles, 2006; Timler, Olswang, \& Coggins, 2005) single-case designs.

Results are organized by the type of development targeted for the participants. The three main sections are cognitive development, social-emotional development, and contextual factors. This organization guides the reader through the characteristics of individuals with FASD as the specific interventions are described in each section. Participants, interventions, and results about the intervention studies are summarized in the Appendix.

\section{RESULTS}

\section{COGNITIVE DEVELOPMENT}

Many children with FASD have a cognitive impairment or have below average intelligence (Howell, Lynch, Platzman, Smith, \& Coles, 2006; McGee, Bjorkquist, Riley, \& Mattson, 2009). A recent study examining medical differences between children with and without FAS suggests that while only $1 \%$ of the population without FAS had a cognitive impairment, it was exhibited in 12\% of the children with FAS (Amendah et al., 2011).

In 2009, McGee et al. found that the intelligence level of individuals with FASD affects their abilities in a variety of areas, such as reading, spelling, and 
communication. McGee and colleagues' research on the expressive and receptive communication skills of children with FASD indicates that although these children have poorer language skills than that of children without prenatal alcohol exposure, their abilities are no worse than expected given their cognitive levels. Similarly, children's reading abilities are comparable to what is expected given their intelligence (Rasmussen \& Bisanz, 2009). This research suggests that children with FASD develop normally in each of these areas, but that development occurs at a slower rate than that of children with average intelligence (McGee et al., 2009). This developmental trend does not extend to mathematics; even when intelligence was controlled children with FASD had poorer performance in mathematics than children who were not prenatally exposed to alcohol (Howell et al., 2006).

Executive Functioning. Executive functioning is a complicated construct that encompasses a series of cognitive processes such as planning (Kalberg \& Buckley, 2007; Skogerbø et al., 2012), inhibition, working memory, and task switching (Davis, Gagnier, Moore, \& Todorow, 2013). It also includes behavioral skills such as "sequencing behavior to efficiently achieve a goal" (Kalberg $\&$ Buckley, 2007, p.279), measures of self-control (Skogerbø, et al., 2012), and using stimulus-reward associations to serve the plan for problem solving (Davis et al., 2013). Overall, executive functioning has been recognized as a central deficit for individuals with FASD (Kodituwakku, 2009; Mattson, Riley, Gramling, Delis, \& Jones, 1998; Rasmussen, 2005;). Challenges in complex working memory, flexibility in cognition, concept formation, and reasoning, highlight some specific difficulties in executive functioning (Kodituwakku, Kalberg, \& May, 2001; Mattson, Goodman, Caine, Delis, \& Riley, 1999). Individuals with FASD usually struggle shifting their attention from one topic to another and are confused by changes in their routine (Coles, Platzman, Raskin-Hood, Brown, Falek, \& Smith, 1997). Therefore, these individuals are challenged and can become frustrated while learning new information, retaining the information, and applying it to new situations.

Neuropsychological profiles for children with FASD identify areas of deficit in intellectual functioning, information processing and integration, attention, and memory (Green et al., 2009; Kodituwakku, 2009). These individuals have substantial difficulties in organization (Pei, Job, Kully-Martens, $\&$ Rasmussen, 2012) and focusing and engaging attention (Mattson, Calarco, $\&$ Lang, 2006). They struggle shifting their attention from one topic to another and are confused by changes in their routine (Coles et al., 1997). For these individuals, the more complex a task becomes, the worse their cognitive functioning performance (Kodituwakku, 2009). However, a recent study has shown improvements in executive functioning skills (e.g. memory, cause and effect, and problem solving) for children with FASD (Wells et al., 2012). 
In a study of younger (aged 4-6) and older children (aged 7-9) with FASD, Rasmussen (2006) found that both age groups struggled with tasks of executive functioning and that working memory was a central weakness. These challenges were correlated with performance on many of the math measures given to the children, indicating that limitations in executive functioning may impact other areas of development and may occur across various developmental stages.

Children with FASD have challenges generalizing learned information to other contexts (Duquette et al., 2006). Some research targeting functional skills has found success generalizing safety skills from virtual reality to realworld contexts (Coles, Strickland, Padgett, \& Bellmoff, 2007; Padgett et al., 2006), but no research was found which specifically explored interventions to ameliorate the limitations children with FASD exhibit in generalization. Further, very few have targeted strategies to improve executive functioning deficits in children with FASD.

Promising Practices: Neurocognitive Habilitation. To lessen the impact of executive functioning limitations, Wells and colleagues (2012) and Bertrand (2009) studied the effectiveness of a neurocognitive habilitation program on the behavior and mathematics functioning of children (aged 6-11) with FASD. Randomly assigned children and families in the intervention group received 12 -weeks of instruction lasting 75 minutes for each of the weekly sessions. Content of the program consisted of group learning activities, transition facilitation, and goodbye rituals (Wells et al., 2012). Review of content was conducted at the end of each week to promote children and caregiver's memory of the practices (Wells et al., 2012). Children in intervention groups demonstrated significant improvements compared to those in the control group, who received no intervention $(\mathrm{p}<01)$ (Bertrand, 2009; Wells et al., 2012). These data suggest that neurocognitive habilitation can improve executive functioning (Bertrand, 2009; Wells et al., 2012), problem solving skills (Wells et al., 2012), and selfregulation (Bertrand, 2009).

Acquisition and Information Processing. Individuals with FASD experience deficits in both the quantity and the quality of the information they process (Burden et al., 2009; Kully-Martens, Pei, Job, \& Rasmussen, 2012). When presented with the same number and type of learning opportunities, children with FASD are likely to learn less information than children without prenatal alcohol exposure (Mattson \& Roebuck, 2002; Roebuck-Spencer \& Mattson, 2004), as well as those with Attention Deficit Hyperactivity Disorder (ADHD) (Crocker, Vaurio, Riley, \& Mattson, 2011). Further, when increasing amounts of visual stimuli are provided, a significant positive linear effect is 
observed for children with FASD in the quantity of time required to process the growing amounts of information (Simmons, Thomas, Levy, \& Riley, 2006). This research is consistent with findings of Engle (2007) suggesting that children with FASD can successfully acquire new information; they just tend to learn at a slower speed than children without prenatal alcohol exposure, especially when large amounts of information are provided.

Promising Practices: Semantic Clustering. Semantic clustering is one learning strategy that may support children with FASD's ability to acquire new knowledge (Kodituwakku et al., 2006; Roebuck-Spencer \& Mattson, 2004). Semantic clustering can be used to group words into categories; for example, apple, banana, and orange could be taught under the cluster of fruit. This grouping may help students with FASD form connections between the words and their meanings, and may make retrieval of the information easier when prompted with the clustering category. Although children with FASD learned less verbal information when presented in a standard format, when the information was presented using semantic clustering, there were no differences exhibited in the learning or memory between children with and without FASD (Aragon et al., 2008b; Kodituwakku et al., 2006; Roebuck-Spencer \& Mattson, 2004).

Promising Practices: Individualizing Instruction. In addition to the research by Roebuck-Spencer and Mattson (2004), Duquette and colleagues (2006) shared tips for teachers that were provided by adolescents with FASD. These individuals indicated that they learn new information better when concepts are taught and re-taught in small amounts and when procedures are given one at a time and repeated. In addition, the adolescents reported that they learn better when opportunities are provided for hands-on learning and concepts are modeled by the teacher. These strategies allow the students more time to process each piece of given information before going on to further learning; the strategies help to ensure that instruction is provided at an appropriate pace so that comprehension can occur. They practices are also consistent with data describing the cognitive profile of individuals with FASD suggesting that teachers should slow the pace that instruction is delivered (McGee et al., 2009) and provide supports to enhance concept formation (Kodituwakku et al., 2001).

Retention. It is well documented that children with FASD have memory deficits (Kully-Martens et al., 2012; Manji, Pei, Loomes, \& Rasmussen, 2010), that generally impact their verbal, visual and working memories (Manji et al., 2010). However, the memory deficits may be less prominent when controlling for initial learning (Mattson \& Roebuck, 2002; Willford, Richardson, Leech, \& Day, 2004). Research indicates that children's memory functioning 
varies according to the degree of prenatal alcohol exposure. For example, children with moderate prenatal alcohol exposure have demonstrated deficits in short-term and long-term memory (Willford et al., 2004), while children with heavy prenatal alcohol exposure have exhibited poor recognition and retention of information previously taught (Crocker et al., 2011).

One aspect of memory that has been rarely investigated in children with FASD is source monitoring (Kully-Martens et al., 2012). Source monitoring is defined as the ability to differentiate internal versus external sources of memory. It is one type of episodic memory that inputs the sensory experience of an important daily function into long-term storage (Johnson, Hashtroudi \& Lindsay, 1993). Research conducted by Kully-Martens and colleagues (2012) examined the overall source monitoring abilities in children (aged 6-12) with FASD by asking them to recall the source of auditory words which were previously presented. Results revealed that children with FASD performed poorly in all source monitoring tasks.

Promising Practices: Rehearsal Training. In their study of a strategy to accommodate children's limitations in memory, Loomes et al. (2008) examined the effectiveness of verbal rehearsal training on the working memory in children (aged 4-11) with FASD. Children in the experimental group received rehearsal training, where they were given instructions to whistle the name of items and numbers repeatedly in their minds, while the control group received no instructions. All children were tested on a digit span task three times (one pretest and two posttests), with only children receiving the rehearsal training significantly increasing in their test scores across the three tests. The results suggest that rehearsal training may help individuals with FASD retain some information previously taught to them.

Mathematics. The amount of prenatal alcohol exposure is positively correlated with the severity of math deficits in children with FASD (Rasmussen \& Bisanz, 2009). Additionally, children with FASD are likely to experience deficits in mathematics, more than other content areas (Carpenter, 2011; Rasmussen, 2006; Rasmussen \& Bisanz, 2009). Therefore, it seems necessary to determine children's intrapersonal strengths and weaknesses in math and to explore interventions to facilitate learning in this content area; to date, several socio-cognitive and neurocognitive practices, as well as modified math curriculum, have been successful.

Promising Practices: Socio-cognitive Habilitation. Kable, Coles, and Taddeo (2007) and Bertrand (2009) examined the impacts of a socio-cognitive habilitative program using modified mathematics curricula. These studies both aimed to improve behavior and mathematics in children (aged 3-10 years) with FASD through the program. Their math intervention program resulted in 
children significantly improving their math knowledge and maintaining the improvements after six months (Coles et al., 2009). All families attended workshops where they were provided information about FASD, advocacy, and behavior regulation and all children received psycho-educational care. The children in the intervention group also received six weeks of tutoring services using modified High Scope Curriculum Series (Kable et al., 2007) or the Math Interactive Learning Experience (Bertrand, 2009). Caregivers in the math intervention groups were instructed to support math learning at home. Results showed a high level of satisfaction for the caregivers and significant gains in their knowledge of FASD, advocacy, and behavior regulation $(\mathrm{p}<.05)$. Both groups of children gained in their math knowledge, with gains for the treatment groups significantly higher than gains in the control groups $(p<.01)$ (Bertrand, 2009).

Functional Skills. It has been well documented that children with FASD have poor adaptive skills (Padgett, Strickland, \& Coles, 2006), sensory processing (Carpenter, 2011; Carr, Agnihotri, \& Keightley, 2010), sensory regulation (Brown, Olson, \& Croninger, 2010; Carpenter, 2011), daily living skills (Crocker, Vaurio, Riley, \& Mattson, 2009), and vocational skills (Spohr, Willms, \& Steinhausen, 2007). In 2008, Edmunds and Crichton found that individuals with FASD struggle finding their place within society. Howell and colleagues (2006) suggest, however, that some functional limitations are the result of prenatal alcohol exposure in combination with contextual factors; their data highlight the possibility that the functional challenges seen in individuals with FASD may be assuaged given high quality home and school environments. Along with the promising practices described below, sensory integration and exercise programs have been identified by teachers as practices that should be considered for individuals with FASD (Carpenter, 2011).

Promising Practices: Virtual Reality Programs. One method used to teach functional skills to individuals with FASD is computer assisted instruction. In 2003, Hamilton and colleagues' research indicated that children with FASD have the visual, motor, and motivational qualities necessary to successfully complete virtual learning tasks. In addition, in 2008, individuals in Edmunds and Crichton's study all had positive experiences with computer programs, and participants mentioned that the computer was less distracting and very enjoyable to use.

Virtual reality programs have been successful in teaching children with FASD fire safety (Padgett et al., 2006) and street safety (Cole et al., 2007). A virtual reality program used to teach children with disabilities safety skills was modified to meet the characteristic needs of children with FASD; these adaptations were additional verbal instructions, visual cues, background music, and 
instruction in navigating the virtual world (Padgett et al., 2006). Children were taught how to perform the assigned task with help from an animated character before they were expected to complete it independently (Coles et al., 2007; Padgett et al., 2006). When the children made correct decisions, the program reinforced them verbally and visually and when an incorrect decision was made, the screen would go black, the danger explained, and they would start from the beginning. In both studies (Coles et al., 2007; Padgett et al., 2006) children learned at least some of the steps of their safety skill, were able to generalize them in a real world simulation, and maintained the learned steps one week later.

In 2007, Strickland, McAllister, Coles, \& Osborne conducted a series of studies using a virtual reality computer based program to train fire and street safety skills. They started with children who had been diagnosed with autism spectrum disorders and then worked with children who had FASD. They changed participants and varied the training content and assessments for five groups of children, but the majority of children who participated demonstrated gains in fire and safety skills and retained their knowledge during a one-week follow-up (Strickland et al., 2007).

Although no research has been completed in the past five years using virtual reality programs with individuals with FASD, it has been effective in promoting the functional skills of individuals with other types of disabilities. Lotan, Yalon-Chamovitz, and Weiss (2010) used a virtual physical fitness program to improve the physical health and heart rates of adults with severe intellectual disabilities. Then, in 2011, Bart et al.'s research improved the attention and self-care abilities of children (aged 6-11) with brain injury. Most recently, Yuen et al.'s (2013) research improved social anxiety, depressive symptoms, and the quality of life for 14 adults with a social anxiety disorder.

Promising Practices: In Vivo Instruction. In vivo instruction is a method in which students are taught and coached on a particular skill in the context of the students' natural environment. In this manner, students have the opportunity to apply skills they have learned in the contexts that have direct application to their lives. The goal of this type of instruction is to enhance the functional use of skills by the participants in their everyday lives.

Adolescents with FASD have indicated that they learn well from interesting hands-on lessons (Duquette et al., 2006; Edmunds \& Crichton, 2008). This suggests that offering participation from among a choice of functional courses or topics may increase students' engagement in the activities and be more meaningful for their future. For example, students working on laundry skills are permitted to choose whether to sort clothes, use the machines, or fold the clothes to practice these functional skills, while giving them input and the opportunity to become invested in the activity. 
Students with FASD have found success in vocational high schools that focus on job skills or other post-secondary training (Duquette et al., 2006). These programs often offer students the opportunity to learn a skill by directly practicing that skill. Supports are often provided by trained staff and then gradually faded to promote students' independence in the task.

In a pilot study of 19 women with FASD, Grant, Huggins, Connor, Pedersen, Whitney, and Streissguth (2004) found success in their community outreach supporting women with FASD with the goal of meeting their identified needs and preventing another generation of prenatally exposed children. The project helped women find housing, enroll in substance abuse treatment programs, receive consistent health care services, and use some method of family planning. Even with this success, the women were still not able to independently function and the advocates in the program emphasized the importance of ongoing supports (Grant et al., 2004).

\section{SOCIAL EMOTIONAL DEVELOPMENT}

Prenatal alcohol exposure negatively effects children's post-natal behavior (Dixon, Kurtz, \& Chin, 2008), even while controlling for confounding variables, such as socioeconomic status and children's intelligence (Mattson $\&$ Riley, 2000). In 2004, Bailey and colleagues' research indicated that prenatal binge drinking was associated with children's behavior problems, but the amount of prenatal alcohol exposure was unrelated to their behavioral outcomes. Day et al. (2013) arrived at a different conclusion indicating that the average daily volume of alcohol consumption during pregnancy and the duration of drinking throughout pregnancy were both predictors of behavioral problems.

Children with FASD have poor social cognition and emotional processing (Greenbaum, Stevens, Nash, Koren, \& Rovet, 2009). They often display deficits in social skills (Carpenter, 2010; Kodituwakku, 2007; Rasmussen, Becker, McLennan, Urichuk, \& Andrew, 2010; Whaley, O'Connor, \& Gunderson, 2001) and are at risk for a variety of social-emotional challenges (Dixon, Kurtz, \& Chin, 2008; Drotar, Aylward, \& Beebe, 2012; Greenbaum et al., 2009). These challenges are exhibited as both internalizing and externalizing behaviors (Graham et al., 2012; Greenbaum et al., 2009; O'Connor \& Paley, 2006; Sood et al., 2001) and are observed by both parents and professionals across environments (Schonfeld, Paley, Frankel, \& O'Connor, 2006).

Internalizing Behaviors. Internalizing behaviors are behaviors that are directed at the individual exhibiting them. These behaviors are more-likely to cause harm to the person performing them rather than others in the environment 
because the individual's emotions are directed inwardly (Rasmussen et al., 2010). Common internalizing behaviors for children with FASD include depression (O'Connor \& Paley, 2006), lack of persistence, forgetfulness, confusion (Graham et al., 2012), and lack of energy (Carr et al., 2010; Edmunds \& Crichton, 2008).

Some internalizing behaviors create specific learning challenges for children with FASD. For example, young children prenatally exposed to alcohol exhibit a more negative affect which in turn impacts the type of interactions between them and their caregivers (O'Connor \& Paley, 2006). Additionally, many school-age children struggle recalling instructions provided orally and following them (Carpenter, 2011). Research also indicates that individuals with FASD experience difficulties meeting learning and behavioral expectations when there are changes in the routine and variations in the tasks presented (Aragon et al., 2008b; Hamilton, Kodituwakku, Sutherland, \& Savage, 2003; Kodituwakku et al., 2001). Teachers have reported success through the use of consistent routines, visual schedules, pairing short concrete directions with visual cues, and repeating instructions and rules as needed (Carpenter, 2011).

Externalizing Behaviors. Externalizing behaviors, directed outwardly, are likely to be disruptive to the learning environment and likely to draw attention to the person performing them and/or cause harm to others. Individuals with FASD have been found to perform a variety of these behaviors, such as hostility (Keil et al., 2010), non-compliance (Ware et al., 2012), mood swings (Carpenter, 2011), lying and stealing (Nash et al., 2006), substance abuse (Burd et al., 2003; Edmunds \& Crichton, 2008), inappropriate sexual behaviors, and trouble with the law (Burd et al., 2003; Streissguth et al., 2004).

Research suggests that children with FASD lack guilt when they misbehave (Caprara et al., 2007; Duquette et al., 2006; Janzen, Nanson, \& Block, $1995)$ and are more likely to lie about their misbehavior when compared with children without prenatal alcohol exposure (Caprara et al., 2007; Rasmussen, Talwar, Loomes, \& Andrew, 2008). Further, Rasmussen et al.'s research indicates that elementary children with FASD are more skilled in telling lies than they were at preschool age. These findings suggest that children with FASD may understand that they can fabricate a story in an attempt to prevent negative repercussions associated with their actions.

Promising Practices: Reinforcement Learning. Although Burd and colleagues' (2003) research highlights the difficulties that may be encountered motivating and rewarding children with FASD, research supports the use of reinforcement as a behavioral support tool for families and professionals (Carpenter, 2011; Engle, 2008; Kurtz et al., 2007) provided that the expectations and rewards remain consistent (Carpenter, 2011). In 2007, a child in Kurtz and colleagues' research decreased in challenging behaviors when 
reinforcement was used as a part of his program. Engle (2008) was able to teach children with and without FASD to select an item from a pair that was more likely to provide a positive response using reinforcement learning. If children selected the correct response, they were likely to receive positive feedback $70 \%$ of the time and negative for $30 \%$. When children selected an incorrect response they received positive feedback $30 \%$ of the time and negative feedback for 70\%. Engle's (2008) research suggests that children with FASD are able to learn from consistent reinforcement, but that the learning may take longer than it does for children who are not prenatally exposed to alcohol. Therefore, to support children with FASD learning with these methods, it is essential that consistent repetition of reinforcement and consequences be provided for behaviors to aid students in learning about the positive or negative effects of their behaviors (Duquette et al., 2006; Engle, 2008).

Promising Practices: Function-Based Interventions. Functional behavioral assessments and behavioral intervention plans are research based methods for determining why children are exhibiting challenging behaviors and determining how to resolve the problem. In 2008, Kurtz and colleagues used these methods to intervene with two toddlers with prenatal exposure to alcohol, cocaine, and heroine who exhibited aggressive and self-injurious behaviors. In their study, Kurtz and colleagues first determined the function of the challenging behaviors to be obtaining attention or tangibles or avoidance of demands. One child was taught to request a preferred item as a replacement for the challenging behaviors. This strategy was effective for the child in two out of three of the conditions presented. The other child was provided reinforcement non-contingently of his behavior every 30 seconds lasting $10 \mathrm{sec}-$ onds; this was paired with ignoring challenging behaviors. This was not effective enough for the child given the dangerous nature of his behaviors, so the ignoring was replaced with a 30 second time-out each time a challenging behavior was exhibited. The combined intervention of non-contingent reinforcement and time-out was effective at decreasing the challenging behaviors for the child.

Attention, Hyperactivity, and Impulsivity. The amount of alcohol consumed prenatally is related to the degree of distractibility and the reaction times for children on performance tasks (Kodituwakku, 2007). Children with FASD are likely to have poor attention spans (Aragon et al., 2008a) and act impulsive and restless (Carpenter, 2011; Janzen et al., 1995; Rasmussen, Becker, McLennan, Urichuk, \& Andrew, 2010). Many also meet the diagnosis requirements for ADHD (Fryer, McGee, Matt, Riley, \& Mattson, 2007), although many professionals rate the social skills of children with FASD as significantly worse than children with ADHD (Greenbaum et al., 2009). The multiple challenges associated with those who have a dual diagnosis may 
compound the social-behavioral limitations and create a unique developmental profile for the population (Ware et al., 2013). For example, individuals with FASD experience challenges focusing their attention and regulating their behaviors which parents and professionals believe may interfere with the learning process (Carpenter, 2011; Kodituwakku, Handmaker, Cutler, Weathersby, \& Handmaker, 1995), leading to poorer social skills, increased problem behaviors (Schonfeld et al., 2006), and interrupted school experiences (Spohr $\&$ Steinhausen, 2008).

Impulsivity is also a struggle for children with FASD (Rasmussen et al., 2010). Parents have reported that their children's impulsive nature is so extreme that they fear for their children's safety (Burgess \& Streissguth, 1992). Although interventions can be used to teach safety skills, if impulsivity is the cause of some safety concerns, it cannot be overlooked. Interventions need to be investigated to determine methods to assist children in managing their impulsiveness and regulating their behaviors.

Both parents and professionals report that children with FASD have more behavioral problems and poorer social skills than children without FASD (Greenbaum et al., 2009). Although research suggests that these problems persist throughout the lifespan for individuals with FASD (O'Connor, 2001; Streissguth, Barr, Kogan, \& Bookstein, 1996), additional research shows that by providing instruction on the rules of social behaviors, modeling appropriate behaviors, and giving home assignments, children can improve their knowledge of appropriate social behaviors and act in more socially appropriate ways (O'Connor et al., 2006).

Promising Practices: Attention Process Training. In 2008, Vernescu randomly assigned 20 children with FASD (aged 6-12) into attention process training and control contact sessions. Materials from the Pay Attention! training protocol were used to teach children the following types of attention: sustained, selective, alternating, and divided. During 12 daily sessions lasting about 30 minutes each, children were provided visual and auditory stimuli to attend. Results show that the attention processing intervention significantly improved children's ability to sustain attention, selection the focus of attention, and alternate attention between sources (Vernescu, 2008).

Computerized Progressive Attention Training (CPAT) is an intervention that targets three neuro-cognitive attention networks responsible for alertness, sensory input, and resolving conflicts (Kerns, Macsween, Wekken, \& Gruppuso, 2010). Ten children (aged 8-15) with FASD completed the 16-hour training program. An average of 30.5 training sessions, lasting about 30 minutes each, were completed one-on-one with a research assistant or teacher. From pre to post testing, children significantly improved their ability to remain focused with distractions present, as well as their sustained and divided 
attention (Kerns et al., 2010). Further, children's reading and mathematics fluency improved.

Friendships. Many children with FASD desire friendships but lack the skills necessary to form and maintain meaningful relationships (Carpenter, 2011). The social emotional challenges (Burgess \& Streissguth, 1992) of children with FASD coupled with their limitations with social skills (CDCP, 2010b) and communication (Kully-Martens, Denys, Treit, Tamana, \& Rasmussen, 2012) propose challenges in establishing friendships. Additionally, children with FASD struggle to identify the emotions of others based upon their facial expressions and to effectively communicate their thoughts (Greenbaum et al., 2009). The interpersonal communication limitations create difficulties in both structured and unstructured situations (KulleyMartens et al., 2012).

Overall, children with FASD perform significantly worse than children without disabilities as well as those with ADHD on measures of socialization (Crocker et al., 2009). These weaknesses also result in the children acting younger than their age, selecting younger friends, being taken advantage of, and not identifying social dangers (e.g. strangers) (Burd et al., 2003; Greenbaum et al., 2009; Janzen et al., 1995). Adolescents and adults with FASD also struggle with relationships, feeling socially accepted, and developing deeper relationships (Duquette et al., 2006). Crocker and colleagues' research in 2009 indicates that performance on socialization tasks for individuals with FASD decrease as children age into adolescence; the authors hypothesized this to be the result of the increasingly complex social demands as children age. Research suggests that individuals with FASD may benefit from counseling and discussions about life or social challenges (e.g. bullying) (Duquette et al., 2006; Edmunds \& Crichton, 2008) or from the use of social stories and scripts (Carpenter, 2011).

Promising Practices: Social Skills Training. In 2005, Timler, Olswang, and Coggins conducted a case study using social-communication interventions with one nine year old girl who was diagnosed with a FASD. The subject received two, one-hour weekly individual intervention sessions, followed by four weeks of group sessions occurring for two hours, three days a week with the subject and two other children with prenatal alcohol exposure. During the individual sessions, the child created a social checklist and a book with socially appropriate behaviors for different situations. The group intervention entailed role playing of social situations, using a checklist as a guide through the social routine, modeling appropriate responses, and an adult reading a social script to the children (Timler et al., 2005). When data were examined across study phases, the subject participated more in the social situation, produced more mental-state verbs, and used more social strategies to resolve conflicts. 
Project Bruin Buddies is a social skills training program aimed at improving peer friendships among children with FASD (Bertrand, 2009). This program was used to teach children (aged 6-12) how to have a conversation with peers, join a play group, participate in at-home play dates, and negotiate to avoid conflict (Bertrand, 2009). This content was the focus of Bertrand's (2009) program; however, the methods of intervention delivery were modified from the original training to account for the children's neurocognitive impairments. In addition to the typical methods, modeling, rehearsal, and performance based feedback were used during play sessions. Each of the 12 sessions lasted 90 minutes and occurred once a week; concurrently, parents attended training sessions for instruction on key social skills and issues related to FASD. At the conclusion of the program, the children had made significant improvements in their knowledge of social behavior $(\mathrm{p}<.0001)$; these findings were aligned with parent data indicating that the child's social skills had improved $(\mathrm{p}<.03)$ and problem behaviors lessened $(\mathrm{p}<.05)$. Further, at post-intervention follow-ups, not only did the children maintain their learned skills, but they continued to improve upon them $(\mathrm{p}<.002)$

The child friendship training (CFT) is another type of social skills training and was examined in three studies with children (aged 6-12) with FASD and their caregivers (Keil et al., 2010; O'Connor et al., 2006; O'Connor et al., 2012). In the studies from 2006 and 2010, children were assigned to either the CFT or delayed treatment control (DTC). The CFT group attended 12 sessions over 12 weeks, lasting 90 minutes in length, while the DTC group would wait to receive the intervention later. The essential social rules being taught to the children were also instructed to the parents using modeling, rehearsal, and performance feedback during the intervention sessions; then, parents were to rehearse the skills at home and coach their child when playing with a peer. In O'Connor and colleagues' study (2006), children in both groups were assessed before and after the treatment, and children receiving the CFT demonstrated gains in knowledge of social behaviors $(\mathrm{p}<.001)$ and actual social skills $(\mathrm{p}<.03)$ as well as reductions in problem behaviors $(\mathrm{p}<.05)$ compared to children in the delayed treatment control (DTC) group. In Keil and colleagues' research, CFT was effective in decreasing children's hostile behaviors for peer group entry $(\mathrm{p}<$ $.05)$, but not for provocation scenarios $(\mathrm{p}=.88)$. Results were maintained at comparable levels in both studies at a three month follow-up.

O'Connor's research from 2012 compared children's social skills before and after receiving the CFT or standard of care (SOC) intervention. The SOC intervention was another social skills training group that taught and discussed a variety of social behaviors; however, the topics were not empirically predictive of peer acceptance, nor was there any parental participation. Comparisons between pre and post testing of the two groups indicated that 
children who received the CFT intervention improved significantly better than children in the SOC on their knowledge of social skills $(\mathrm{p}<.001)$, their self-concept $(p<.05)$, and parental reports of children's assertion $(p<.05)$ and responsibility $(\mathrm{p}<.05)$, but not cooperation $(\mathrm{p}=.59)$ or self-control $(\mathrm{p}=.39)$. These results confirm previous findings that CFT positively impacts children's social knowledge and skills, but that a modification to the intervention may be necessary to target some of the specific social-behavioral needs of children with FASD.

Promising Practices: Social-Behavioral Therapies. In Bertrand's (2009) comparative study of parent-child interaction therapies, families received either the Parent-Child Interaction Therapy (PCIT) or the Parenting Support and Management (PSM) program across 14 weeks, with each weekly session lasting 90 minutes. Two of these sessions included in vivo coaching using bug-in-ear (BIE) technology for the PCIT group. BIE is a method of coaching in which performance based feedback is provided to a parent (or professional) through an earpiece while he/she is interacting with a child. Feedback from Bertrand's study focused on teaching parents behavioral management skills. The other 12 sessions entailed both the parent and child interacting with one another. Children in both groups improved on their behaviors with non-significant differences favoring the PCIT group $(\mathrm{p}=.14)$. In addition, caregivers in both groups found their program favorable and $80 \%$ indicated that they would recommend the program to others (Bertrand, 2009).

Another behavioral study compared the Families Moving Forward (FMF) program with families receiving standard community care (Bertrand, 2009). The FMF program lasted 9-11 months with families receiving sessions in their home lasting 90 minutes every other week. Each session focused on improving attitudes about children's challenging behaviors and empirically based methods caregivers could use to manage them. Results indicate that families' needs were better met $(\mathrm{p}<.01)$ and children's behaviors improved significantly $(\mathrm{p}<.05)$ for families in the FMF group compared to children receiving standard comminity care (Bertrand, 2009).

Other intervention studies that have shown significant results in child skills and performance also had involvement of parents or caregivers as one component. For example Kable and colleagues (2007) provided training to parents and caregivers to increase their knowledge about characteristics of FASD, as well as providing methods to support their children's learning in mathematics. Additionally, Coles, Kable, and Taddeo (2009) focused on teaching parents methods for enriching the home environment to support their children's learning of math skills. These studies suggest that involving peers and parents in the intervention can positively impact the social, behavioral, and/or cognitive learning in children with FASD. 


\section{CONTEXTUAL FACTORS}

In the United States, approximately $50 \%$ of pregnancies are not planned (CDCP, 2011). Even if a woman has the knowledge that she should not drink alcohol while she is pregnant, she may go weeks without learning of her pregnancy and drink during that time. In documented instances of this phenomenon, many women report feelings of grief and shame upon learning that their child's challenges may have been prevented had they not consumed alcohol during their pregnancy (Hope for Women in Recovery Summit, 2005). For children with FASD, there are a combination of biological and environmental factors that interplay and impact the children's development and learning (Kully-Martens et al., 2012).

When families have a child with a developmental delay, typically, the entire family is significantly affected (Bailey, Golden, Roberts, \& Ford, 2007; Skinner \& Weisner, 2007). Caregivers of children with FASD have reported this impact on their family (Rowbottom et al., 2010). Parents are frustrated with the lack of supports and services available to them and their child (Ryan $\&$ Ferguson, 2006). They often experience heightened stress and financial strain as a result of conditions associated with the disability (Olson, Oti, Gelo, $\&$ Beck, 2009b). The greatest challenge for these parents is dealing with their child's behaviors (Ryan \& Ferguson, 2006). Families have also reported adverse experiences with professionals; therefore, parents often must become directly involved in their child's services to ensure that they receive the attention they need (Olson et al., 2009b). Since the family environment impacts a child's development, it is essential to include the family in intervention planning (Olson et al., 2009b).

Home Environment. High quality, structured caregiving and a positive home environment are among the best protective factors for children with FASD (Streissguth, 1997; Streissguth, Bookstein, Barr, Sampson, O’Malley, \& Young, 2004). Unfortunately, “...a positive and stable environment during childhood is not typical for this population" (Olson, 2009b, p. 237). In fact, children with FASD are likely to experience additional risk factors such as exposure to other tetragons prenatally (O'Connor \& Paley, 2006; Streissguth et al., 2004), postnatal trauma (Coggins, Timler, \& Olswang, 2007), poverty and poor nutrition (May et al., 2009), and multiple living placements (Greenbaum et al., 2009) that increase the likeliness of lifelong challenges. Although family support services are valuable for all children with FASD, Jirikowic, Gelo, and Astley (2010) found that it may be even more important for children birth through two years of age, compared with children three years and older $(\mathrm{p}=.01)$.

Children with FASD often live with individuals who are not their biological parents (Jirikowic et al., 2010). These environments are typically more 
stable for the children and support healthy growth and development (Rowbottom et al., 2010). But many non-biological caregivers face challenges associated with raising a child with a FASD that negatively affect their emotional well-being and home environment (Rowbottom et al., 2010). Little research has specifically targeted adoptive or foster families in research; practices need to be investigated about methods that can better prepare these families for FASD and the challenges the family may incur as a result of the disability (Rowbottom et al., 2010).

Support Groups. Participation in family support groups may be particularly important for parents who have a child with FASD. Johnston and Mash (1989) found that the number one unmet need identified by caregivers of children with FASD was the opportunity to talk with other individuals who have gone through similar experiences. This need for support has not changed over the years; in 2009, parents were still reporting this need (Olson et al., 2009b).

The two primary types of support groups for families are parent support networks and FASD specific parent support organizations (Olson et al., 2009b). Parent support networks are broad groups that can include caregivers of children who have any type of disability or challenging condition, while FASD specific organizations are for caregivers who have a child with a FASD. Both types of support groups are helpful in providing information and resources from other parents or professionals and they serve as socialemotional networks that allow for families to give and receive support from one another (Olson et al., 2009b). The support groups are centered on family needs; discussion tends to focus on solutions to problems and parents often improve upon their advocacy skills after participation in support groups (Olson et al., 2009b).

Although support groups are highly recommended by professionals, research has not examined the impact of support groups on family and child outcomes. These studies could be an appropriate avenue to include siblings' perspectives and supports to gain knowledge about the impact of FASD on family members other than caregivers. It could also provide all family types (e.g. biological, foster, and adoptive) with strategies on effective child rearing methods that can aid in stress management (Olson et al., 2009a), challenging behaviors (Ryan \& Ferguson, 2006), and positive relationships (Olson et al., 2009b).

\section{IMPLICATIONS}

A plethora of research data exists describing the characteristics and challenges of individuals with FASD (Ware et al., 2013). These data are valuable given that adolescents with FASD have identified their best teachers as those who are 
knowledgeable about the disability and its impacts on learning and behavior (Duquette et al., 2006). Therefore, an important implication of this research is to increase the awareness of FASD and to develop more effective methods to disseminate knowledge and resources to professionals working with these individuals. These professionals will be more likely to acquire effective interventions and evidence based practices to meet the needs of children with FASD. The following aspects of assessment and planning are considered: the child's developmental portfolio, the environmental and task structure, self-determination, and caregiver involvement.

\section{ASSESSING THE CHILD'S DEVELOPMENTAL PORTFOLIO}

This research review has documented the cognitive (Mattson et al., 2013), functional (Crocker et al., 2009), sensory (Carr et al., 2010), and social emotional (Ware et al., 2013) limitations of individuals with FASD. It has also identified interventions that target these areas in an effective manner for the population (Green, 2007; Kodituwakku, 2010). This is beneficial because children with FASD have a unique set of strengths and weaknesses that, when considered through assessment and planning, maximize the effectiveness of an academic program (Burd et el., 2003; Carpenter, 2011; Janzen et al., 1995).

For children with FASD, the impact of prenatal alcohol exposure on their thoughts and actions need to be examined in the context of their developmental profile (Janzen et al., 1995; Mattson et al., 2013). Although this is not a novel recommendation the validity lies in the research suggesting that families are still under a great deal of stress because of their children's behavioral difficulties, and professionals continue to lack in their knowledge of FASD (Olson et al., 2009b). For children with FASD:

Effective interventions must consider the interplay between behavioral symptoms and the neuropsychological effects of prenatal alcohol exposure...instead of viewing a child's difficulties or behavior problems as a result of the child being defiant, lazy, intentional, or manipulative, these behaviors should be viewed as symptoms of neurocognitive deficits. (Green, 2007, p.106)

If children with FASD are viewed in such a manner, professionals who work with them and their families are more likely to provide instruction and behavioral supports in a positive manner (Green, 2007). This could be one factor that improves the services families receive from professionals (Olson et al., 2009b; Ryan \& Ferguson, 2006). In order for this to occur, improvements are warranted in how children with FASD are diagnosed and assessed (Brown et al., 2010). 
Screening. Over the past decade professionals have used a variety of screening measures to identify children who may have prenatally been exposed to alcohol (Poitra et al., 2003; Zelner et al., 2012). These screening methods have begun as early as prenatal (Chang, 2004) and extended as late as kindergarten enrollment (Poitra et al., 2003).

The T-ACE is a four-item questionnaire that physicians can ask pregnant mothers during prenatal appointments to gauge prior alcohol usage and red flags for current alcohol use during pregnancy (Chang, 2004). T-ACE is an acronym for the questions asked relating to the mother's tolerance, annoyance, cutting-down, and eye-opening experiences with drinking alcohol. Women can receive between zero and five points on the T-ACE with scores of two or higher indicating the mother may be at risk for alcohol consumption during pregnancy. Research suggests that when mothers were given a brief intervention after receiving a two or higher, women were more likely to refrain from alcohol use or decrease their consumption throughout the pregnancy (Chang, 2004). Mothers received the following four steps of intervention: 1) assessment and direct feedback, 2) goal setting, 3) usage of behavioral modification techniques, and 4) resources on self-help and reinforcement.

One challenge that arises with the T-ACE screening is the reliability of mothers' responses (Chang, 2004). The Timeline Followback calendar (TLFB) is another screening measure that uses the date of conception and the date the woman realized she was pregnant to assess the frequency and amount of alcohol consumed during pregnancy (Caprara et al., 2007) Caprara et al. suggest combining the T-ACE with the TLFB to increase the accuracy and effectiveness of screening for alcohol consumption during pregnancy. A flaw with prenatal screening is that women who do not visit a physician during pregnancy would not be evaluated using these methods.

Another method of screening for prenatal alcohol exposure is neonatal screening (Hopkins et al., 2008; Zelner et al., 2012). This method uses maternal biomarkers from the fatty acid ethyl esters (FAEE) in the newborn's meconium, earliest stools (Zelner et al., 2012). Although this method does not detect alcohol consumption for the entire pregnancy, it provides an accurate history for the second and third trimesters (Caprara et al., 2007). The early screening of FASD would have significant cost benefits to society if the majority of children were identified (Hopkins et al., 2008). However, Zelner et al.'s research suggests that if the meconium screening measure is optional, many women who have consumed alcohol during their pregnancy are likely to opt out of the procedure; this is problematic because the children most likely to test positive are likely to be the ones not screened. Methods should be considered to encourage more women to consent to screening (Zelner et al., 2012) or to make neonatal screening more universal (Hopkins et al., 2008). 
A third method used to screen for FASD is adding a test form to the additional assessments for early intervention (Watson et al., 2011) or kindergarten screening (Poitra et al., 2003). The benefits of this screening are that it only takes 10 minutes to administer, it is feasible to add into the other assessments, and it is cost efficient. The downsides are the relative lateness of the screening, the diminished growth delays with the child's age, and the increased likeliness that the child lives with non-biological parents and relevant information unknown by the current caregivers (Burd, Klug, Li, Kerbeshian, \& Martsolf, 2010). Overall, adding an FASD screening can be helpful in raising awareness of FASD and identifying children at risk for it (Watson et al., 2011).

Regardless of the screening method utilized, it is imperative that families and professionals know that screening positive does not mean that child has FASD. A screening is merely a tool to identify children at risk for FASD who may or may not have a diagnosis after further testing (Caprara et al., 2007).

Diagnosis. The authors agree with the National Task Force on Fetal Alcohol Syndrome and Fetal Alcohol Effects that modifications are necessary in the diagnostic process for children with FASD (Olson et al., 2009a). One change should occur at the policy level so that children with any diagnosis on the fetal alcohol spectrum can be eligible for services, if needed (Brown et al., 2010). Current diagnostic practices for FAS should be evaluated to determine if they could be adapted for the other FASD conditions, since there is "no definitive test for FASD" (Pei \& Rinaldi, 2004, p.126). Currently, about $75 \%$ of children are accurately diagnosed with FASD or evaluated as non-FASD (Mattson et al., 2013). FASD measures need to be validated so that children can be understood appropriately with one of the FASD conditions without going unrecognized or misidentified (Olson et al., 2009a) even if other conditions exist that may confound some characteristics of FASD (Bishop et al., 2007). This may entail improving current diagnostic methods (Ware et al., 2013) or exploring new methods of diagnosis, such as brain imaging (Wozniak, et al., 2011) and using Telehealth for FASD assessments (Ens, Hanlon-Dearman, Millar, \& Longstaffe, 2010).

Complete Assessments. Children with FASD are often diagnosed from symptoms and then the specific areas of atypical development are examined further to better understand the children's unique profiles (Pei \& Rinaldi, 2004). Individuals with FASD experience challenges in multiple developmental areas and therefore, to develop a thorough child profile, a variety of assessments should determine the child's strengths and limitations (Pei \& Rinaldi, 2004). A thorough assessment will shed light on the neurocognitive and neurobehavioral development of the child (Mattson et al., 2013), as well as identify any adaptive or sensory needs (Burd et al., 2003). This will help professionals understand the impact of the child's prenatal alcohol exposure on their learning and behavior, and equip them with the skills to provide services for children with FASD and their families (Brown et al., 2010). Since instruc- 
tional accommodations are more likely to be necessary as children increase with age ( $\mathrm{p}=.009)$, it is probable that complete assessments for children with FASD should occur routinely to guarantee that the information is current and relevant for the child's academic and/or behavioral plan (Jirikowic et al., 2010).

\section{PLANNING THE ENVIRONMENTAL AND TASK STRUCTURE}

Early Intervention. Research highlights the importance of interventions throughout the lifespan (Fagerlund et al., 2006; Spohr \& Steinhausen, 2008). In 1994, Williams and Howard reported the necessity for interventions to meet the needs of children with FASD; 20 years later, this is still an imperative need (Goodlett, 2010). Although intervention research for school age children with FASD is limited (18 studies), it is even scarcer for very young children (1 study) and adults ( 2 studies). It is well documented that children with developmental delays or disabilities benefit from early intervention (Burgess \& Streissguth, 1992; Goodlett, 2010). For children with FASD, early intervention is a protective factor that increases the likeliness of positive outcomes (Streissguth, Barr, Kogan, \&Bookstein, 1996). If screening and diagnosis practices improve for this population, then early identification is more likely and child and family services can begin at a younger age (Goodlett, 2010).

Since family resources are especially valuable for children birth through two years, research targeted family-centered interventions may be particularly meaningful for this population (Belcher et al., 2005; Jirikowic et al., 2010). For example, providing home-based and/or center-based services for families of children with pre-natal drug exposure has resulted in improvements for both caregivers and children (Belcher et al., 2005). Caregivers improved in responsive interactions (Lowe, Handmaker, \& Aragon, 2006; O'Connor \& Paley, 2006), increased their parenting knowledge, decreased corporal punishment, and reduced stress and depression (Belcher et al., 2005). Targeted interventions for children beginning at a younger age provide supports for aspects of the disability that emerge early in life, such as growth deficiencies (Belcher et al., 2005), information processing (Stephen et al., 2012), negative affect, and emotional regulation (Lowe et al., 2006; O'Connor \& Paley, 2006).

Individualization. For school aged children Ryan and Ferguson's (2006) research suggests that experienced teachers are better equipped to meet the needs of students with FASD, compared to novice ones. Their research indicates that experienced teachers differentiate instruction while novice teachers struggle to do so. In 2010, Blackburn and Whitehurst's study demonstrated that teachers are more successful educating children with FASD when their instruction is visual and concrete (Blackburn \& Whitehurst, 2010). One teacher highlighted the importance of repetition in both teaching and rules/directions when she indicated that for her students it is "Here today, gone tomorrow!" (Carpenter, 2011, p. 39). 
Individualization is not only important for academic tasks, but also for behavior modification. Students excel behaviorally when interventions are consistent (Engle, 2008) and opportunities are provided for students to self-monitor their behaviors (Green, 2007). Although numerous practices are available for professionals to implement, Bertrand (2009) found that these interventions could be more effective for individuals with FASD if they are personalized to the children's neurocognitive and behavioral characteristics. For example, since many individuals with FASD have difficulties with sensory processing, planning ongoing activities that allow them to integrate their senses can be beneficial in preventing sensory related challenging behaviors (Carpenter, 2011).

Structure. Routines and consistency cannot be overlooked when working with individuals with FASD. Researchers have documented the unpredictable nature of the population (Carpenter, 2011) and the challenges they face switching between concepts and expectations (Mattson et al., 2012). The difficulties experienced with changes in activities impact these individuals both academically and behaviorally, because they struggle adjusting to the new demands (Burd et al., 2003). Having clear structure, physical or visual boundaries, and set schedules can greatly aid children with FASD in navigating their environment and learning from it (Burd et al., 2003; Carpenter, 2011).

Transition. As adolescents transition into adulthood their need for support does not diminish (Fagerlund et al., 2006), yet the resources available to them may (Clark, Minnes, Lutke, \& Ouellette-Kuntz, 2008). Adults with FASD often struggle finding and keeping employment and housing, and remaining drug free (Edmunds \& Crichton, 2008; Grant et al., 2004). Adolescents may need a stronger emphasis on functional skills while in school and additional functional and vocational supports into adulthood (McGregor, 2009; Spohr \& Steinhausen, 2008). These findings are derived from exploratory qualitative studies; they highlight many challenges associated with adolescents and adults with FASD, but, with the exception of the community intervention pilot study (Grant et al., 2004), they do not offer interventions that could be effectively implemented with the population to improve their independence as an adult. Researching these practices is imperative to improve the quality of life for adults with FASD (McGregor, 2009) and to help prevent the cycle of prenatal alcohol exposure (Grant et al., 2004).

\section{PLANNING FOR SELF-DETERMINATION}

While certain aspects of self-determination can be targeted while children are young (e.g. choice making, safety, and reinforcement skills), these skills become increasingly more important as children reach adolescence and adulthood (McGregor, 2009). Although adults with FASD are at an increased risk 
to attempt suicide, having the responsibility to care for a child or to mentor others may diminish the likelihood of this irreversible action (McGregor, 2009). Improving self-determination can affect an individual's quality of life and lead to better life-long outcomes.

Independence. Individuals with FASD are likely to need assistance in their daily living. Whether targeting academic or functional skills, the individual's independence can be promoted if professionals provide the supports required and then fade the supports when they are no longer necessary. For older individuals, one method to assist them in feeling like adults is to allow them to make their own decisions (McGregor, 2009). Teaching individuals with FASD to problem solve and make their own choices and decisions can be helpful in promoting their independence and improving their quality of life.

Self-regulation. Individuals with FASD have diminished abilities to selfregulate their behaviors and self-calm in escalated situations (Carpenter, 2011). These challenges make it more likely that the population will "over-react" to their environment (Carpenter, 2011). Additionally, these individuals do not learn well from their mistakes and they often need multiple chances to re-try tasks they previously failed (McGregor, 2009). These individuals may also need more time to realize the value in rules and the importance of following them.

Self-realization and Psychological Empowerment. Adults with FASD have indicated that learning about their disability and how it impacts them has aided in understanding themselves and some of their challenges (e.g., increased vulnerability to additions) (McGregor, 2009). As children enter adulthood, they may choose not to volunteer that they have a disability with prospective employers or universities because of embarrassment or a strong will; they may attempt to independently cope with their struggles which could create problems in both of these environments and result in the lack of accommodations and supports necessary to be successful (McGregor, 2009). Developing a strong sense of self can help individuals with FASD be aware of their abilities and accept advice and assistance when needed.

Skill development can help promote a more positive sense of self. It is important to consider the abilities of individuals with FASD, because impairments do not exist in all areas (Jantzen et al., 1995). Intrapersonal strengths should be used to tailor instruction and adapt interventions so children with FASD can feel successful while improving in areas of weakness. One of the most important factors to help children with FASD understand is that they are capable of learning. Many individuals with FASD have prior school experiences that are negative (Duquette et al., 2006). Not only do educators face the challenge of teaching their students, but they also must help the students believe in themselves and be motivated learners; this can happen through continual successes in school. As professionals begin to shift their thinking about FASD, they are more likely to 
patiently instruct students instead of critically punishing them (Green, 2007). Table 1 provides a summary of specific development research for children with FASD and practices that have some research to support their efficacy.

\section{PLANNING FOR CAREGIVER INVOLVEMENT}

Early Years. Caregiver involvement needs to begin before pregnancy. Researchers have established numerous characteristics of mothers who are at the highest risk of birthing a child with FASD that can help guide the development of preventative programs (Cannon, Dominique, O'Leary, Sniezek, \& Floyd, 2012; May et al., 2009). A need exists for additional research exploring methods to improve the prevention of FASD and partnerships with community organizations so that education and resources can be disseminated to greater numbers of people and target the populations with the highest risk factors (Arendt $\&$ Farkas, 2007; Hanson, Winberg, \& Elliott, 2012). For example, since the majority of mothers who have a child with FASD are single or cohabitating, providing a support network could be especially helpful for meeting the unique needs of these mothers (Cannon et al., 2012).

School Age. Advocacy is the process of arguing in favor of something. Many individuals with FASD lack self-advocacy skills and rely on others to advocate for them (McGregor, 2009). Duquette and colleagues' (2006) found that caregiver advocacy is a protective factor increasing adolescent persistence to graduate from high school. Additionally, some successful interventions have involved parents and caregivers as facilitators for academic, social, and behavioral interventions (Bertrand, 2009). The majority of these programs have included caregiver workshops that teach parents about the effects of prenatal alcohol exposure and behavioral or cognitive strategies that could be useful when interacting with their child (Kabel et al., 2007). The use of parent facilitated strategies has helped parents act more responsively with their children (Lowe et al., 2006) and increased the children's learning over time (Bertrand, 2009).

Adulthood. Another factor adding to the importance of caregiver involvement is the dependence adults with FASD may have on their caregivers (McGregor, 2009). Seventy percent of adults with FASD live dependently and are unemployed (Spohr \& Steinhausen, 2008; Spohr, Willms, \& Steinhausen, 2007) with most being fired or resigning from numerous jobs (McGregor, 2009). If community integration is achieved, it is partially the result of emotional and financial support from friends and family (Clark et al., 2008). Providing these supports typically fall onto caregivers, who often take the responsibility of caring for their child longer than the societal norms of childrearing. In addition to these obligations, there is also added stress to families who try to plan for the care of their child in the event of their death (Clark et al., 2008). 
Table 1.

Methods to Support Children with FASD

\begin{tabular}{|c|c|c|}
\hline $\begin{array}{l}\text { Developmental } \\
\text { Area }\end{array}$ & $\begin{array}{l}\text { Developmental } \\
\text { Research }\end{array}$ & $\begin{array}{c}\text { Evidence-Based Practices } \\
\text { Research }\end{array}$ \\
\hline \multirow[t]{2}{*}{ Cognition } & $\begin{array}{l}\text { Children with FASD are more } \\
\text { likely to have cognitive impair- } \\
\text { ments than children who are typi- } \\
\text { cally developing. }\end{array}$ & \\
\hline & $\begin{array}{l}\text { Executive functioning and working } \\
\text { memory are central deficits. }\end{array}$ & $\begin{array}{l}\text { - Neurocognitive habili- } \\
\text { tation program }\end{array}$ \\
\hline $\begin{array}{l}\text { Intelligence } \\
\text { Comparison }\end{array}$ & $\begin{array}{l}\text { Children's performance in reading, } \\
\text { spelling, and communication are } \\
\text { comparable to levels expected for } \\
\text { their intelligence. }\end{array}$ & \\
\hline Pacing & $\begin{array}{l}\text { Development and learning occurs } \\
\text { in typical patterns for children with } \\
\text { FASD, compared to those who are } \\
\text { typically developing, but the rate of } \\
\text { learning is typically slower. }\end{array}$ & $\begin{array}{l}\text { Teach and re-teach } \\
\text { content in smaller } \\
\text { amounts and at a } \\
\text { slower pace }\end{array}$ \\
\hline Acquisition & $\begin{array}{l}\text { When presented with the same } \\
\text { amount of information, children } \\
\text { with FASD usually acquire less } \\
\text { information than children who are } \\
\text { typically developing. }\end{array}$ & $\begin{array}{l}\text { - Semantic clustering } \\
\text { - Hands-on learning } \\
\text { - Teacher modeling } \\
\text { - Concrete examples }\end{array}$ \\
\hline $\begin{array}{l}\text { Retention } \\
\text { Generalization }\end{array}$ & $\begin{array}{l}\text { Retention and generalization of } \\
\text { information can be problematic. }\end{array}$ & - Rehearsal training \\
\hline Mathematics & $\begin{array}{l}\text { Mathematics is a limitation, even } \\
\text { when controlling for intelligence. }\end{array}$ & $\begin{array}{l}\text { - Neurocognitive habili- } \\
\text { tation program } \\
\text { - Socio-cognitive habili- } \\
\text { tation program } \\
\text { - Modified mathematics } \\
\text { curricula }\end{array}$ \\
\hline \multirow[t]{2}{*}{ Functional Skills } & $\begin{array}{l}\text { Adaptive skills are problematic and } \\
\text { parents sometimes fear for their } \\
\text { children's safety. }\end{array}$ & $\begin{array}{l}\text { - Virtual reality programs } \\
\text { - In vivo instruction }\end{array}$ \\
\hline & $\begin{array}{l}\text { Adolescents and adults need sup- } \\
\text { port with vocational skills, finding, } \\
\text { and keeping a job. }\end{array}$ & $\begin{array}{l}\text { - Vocational programs } \\
\text { - Post-secondary training } \\
\text { - Community outreach } \\
\text { programs }\end{array}$ \\
\hline
\end{tabular}


Table 1. (Continued)

\begin{tabular}{|c|c|c|}
\hline $\begin{array}{l}\text { Developmental } \\
\text { Area }\end{array}$ & $\begin{array}{l}\text { Developmental } \\
\text { Research }\end{array}$ & $\begin{array}{c}\text { Evidence-Based Practices } \\
\text { Research }\end{array}$ \\
\hline Social Emotional & $\begin{array}{l}\text { Deficits exist in social skills and } \\
\text { individuals usually have both inter- } \\
\text { nalizing, externalizing behavioral } \\
\text { challenges. }\end{array}$ & $\begin{array}{l}\text { - Social-behavioral } \\
\text { therapy } \\
\text { - Socio-cognitive habili- } \\
\text { tation program } \\
\text { - Self-monitoring } \\
\text { - Reinforcement } \\
\text { learning } \\
\text { - Consistency in } \\
\text { outcomes }\end{array}$ \\
\hline Hyperactivity & $\begin{array}{l}\text { Many children are hyperactive } \\
\text { and/or impulsive in their behaviors. }\end{array}$ & $\begin{array}{l}\text { - Social-behavioral } \\
\text { therapy } \\
\text { - Self-monitoring }\end{array}$ \\
\hline Attention & $\begin{array}{l}\text { Shifting attention and changes in } \\
\text { the routine are cumbersome. }\end{array}$ & $\begin{array}{l}\text { - Attention processing } \\
\text { training }\end{array}$ \\
\hline Friendships & $\begin{array}{l}\text { Individuals struggle forming } \\
\text { friendships and deeper relation- } \\
\text { ships. }\end{array}$ & $\begin{array}{l}\text { - Peer and caregiver } \\
\text { implemented social } \\
\text { skills training programs }\end{array}$ \\
\hline
\end{tabular}

Note: $\mathrm{FASD}=$ Fetal alcohol spectrum disorder; PAE $=$ Prenatal alcohol exposure

\section{DISCUSSION}

Effective practices to prevent FASD and intervene with the associated challenges are going to take the combined effort of policymakers, researchers, and communities (Kyskan \& Moore, 2005). The impact of these efforts could be screening and diagnostic procedures that identify more children with FASD earlier in life. This identification and intervention can assist children and families in a time of critical development for the child and promote healthy home environments and caregiving. These factors could substantially minimize later challenges and economic burdens for families and communities.

Now that a substantial data base has been acquired on the developmental characteristics of children with FASD, interventions need to be studied to determine the best methods to meet the needs of these individuals. It is imperative that this research covers the entire lifespan of the individual to ameliorate challenges at various stages of life, substantially improve the education for individuals with FASD, and improve the quality of life for them and their families. 


\section{Appendix}

Summary of Instructional Studies for Individuals with FASDs

\begin{tabular}{|c|c|c|c|}
\hline $\begin{array}{l}\text { Research Design } \\
\text { Bertrand (2009) }\end{array}$ & $\begin{array}{l}\text { Participant } \\
\text { Description }\end{array}$ & Research Focus & Results \\
\hline $\begin{array}{l}5 \text { randomized con- } \\
\text { trolled studies; } \\
\text { pre-post testing }\end{array}$ & $\begin{array}{l}\text { All had FASD } \\
\text { 1. } 100 \text { children } \\
\text { 6-12 years-old } \\
\text { Avg. IQ }-97 \\
\text { 2. } 61 \text { children } \\
\text { 3-10 years-old } \\
\text { Avg. IQ }-81 \\
\text { 3. } 78 \text { children } \\
\text { 6-11 years-old } \\
\text { Avg. IQ }-90 \\
\text { 4. } 58 \text { children } \\
\text { 3-7 years-old } \\
\text { Avg. IQ }-88 \\
\text { 5. 52 children } \\
\text { 5-11 years-old } \\
\text { Avg. IQ }-94\end{array}$ & $\begin{array}{l}\text { All projects included } \\
\text { pre/post testing } \\
\text { 1. Children's friend- } \\
\text { ship training; } \\
12 \text { weekly sessions } \\
\text { lasting } 90 \text { min.; } \\
3 \text { mo. follow-up } \\
\text { 2. Socio-cognitive } \\
\text { habilitation pro- } \\
\text { gram; } 2 \text { caregiver } \\
\text { workshops; } \\
6 \text { weeks of tutor- } \\
\text { ing using a modi- } \\
\text { fied math } \\
\text { curriculum } \\
\text { 3. Neuro-cognitive } \\
\text { habilitation, tar- } \\
\text { geting behavior } \\
\text { regulation; } \\
12 \text { weekly sessions } \\
\text { lasting } 75 \text { min. } \\
\text { 4. Comparison of } \\
\text { parent-child inter- } \\
\text { action and parent- } \\
\text { only therapy; } \\
14 \text { weekly sessions } \\
\text { lasting } 90 \text { min. } \\
\text { 5. Comparison of } \\
\text { Families Moving } \\
\text { Forward and stan- } \\
\text { dard community } \\
\text { care; } 9-11 \text { mo. } \\
\text { of training every } \\
\text { other week lasting } \\
90 \text { min. }\end{array}$ & $\begin{array}{l}\text { 1. Children in the } \\
\text { intervention group } \\
\text { significantly } \\
\text { improved in their } \\
\text { knowledge of social } \\
\text { behaviors and } \\
\text { actual social skills } \\
\text { \& decreased in } \\
\text { their problem } \\
\text { behaviors } \\
\text { 2. Caregivers were sat- } \\
\text { isfied with the pro- } \\
\text { gram and improved } \\
\text { in their knowledge } \\
\text { Children made } \\
\text { significant gains in } \\
\text { their math } \\
\text { knowledge } \\
\text { 3. Children made sig- } \\
\text { nificant improve- } \\
\text { ments in their } \\
\text { executive function- } \\
\text { ing, problem solv- } \\
\text { ing, \& behavior } \\
\text { regulation } \\
\text { 4. Children in both } \\
\text { groups improved } \\
\text { in their behaviors } \\
\text { Both groups of } \\
\text { caregivers found } \\
\text { their program } \\
\text { favorable } \\
\text { 5. Family needs were } \\
\text { better met and } \\
\text { children's behav- } \\
\text { iors significantly } \\
\text { improved in the } \\
\text { intervention group }\end{array}$ \\
\hline
\end{tabular}


Appendix. (Continued)

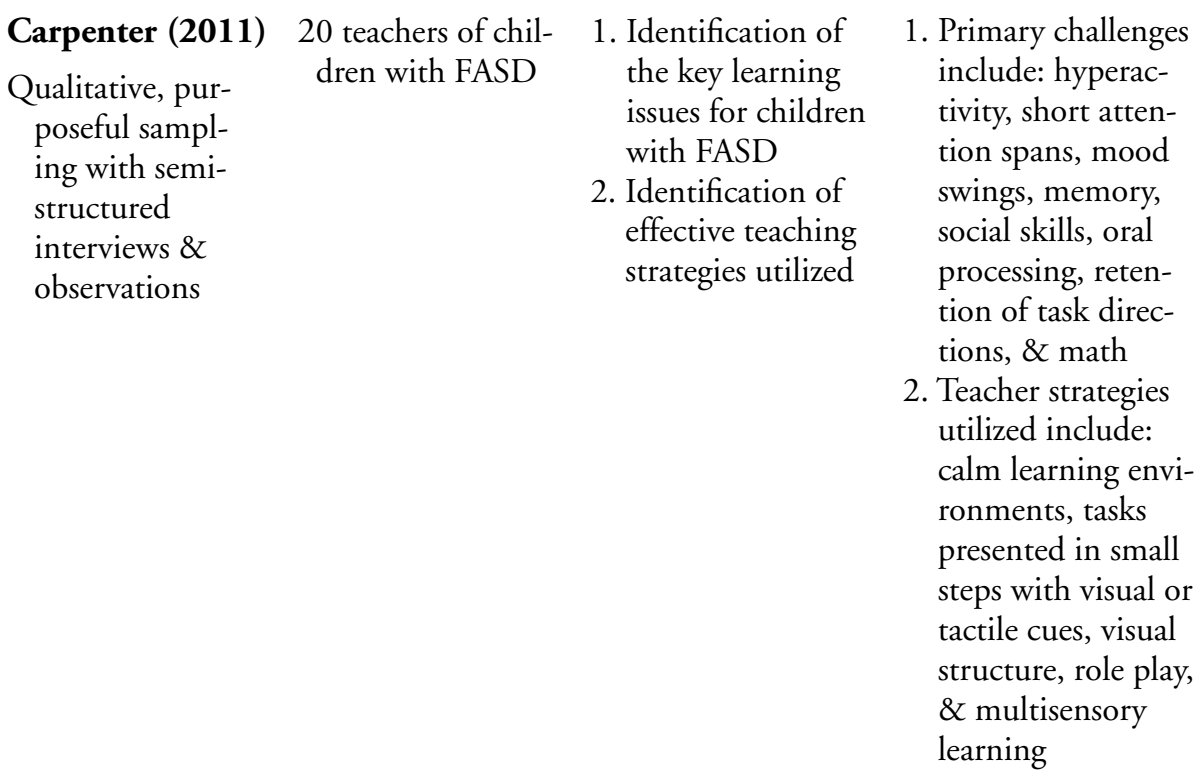

$\begin{array}{ll}\text { Coles, Kable, \& } & 54 \text { children } \\ \text { Taddeo (2009) } & \text { 3-10 years-old } \\ \text { Randomized } & \text { All had FASD } \\ \text { controlled study; } & \text { IQs }>50 \\ \text { pre-post testing } & \end{array}$

Duquette, Stodel, 8 adolescents with Fullarton, \& FASDs and their Hagglund (2006) adoptive parents Qualitative, case 15-20 years-old study

$\begin{array}{ll}\text { Edmunds \& } & 5 \text { adolescents } \\ \text { Crichton (2008) } & \text { 16-20 years-old } \\ \text { Qualitative, ethnog- } & \text { All had FASD } \\ \text { raphy } & \end{array}$
Parents' workshops
6 weeks of math intervention using a modified math curriculum
6 mo. later, post- test 2

Student Integration Model used to explore student dropout and persistence to graduate

The impact of a customized program on the learning, confidence, awareness, \& employment of individuals with FASD
At post-test 2, there were significantly greater scores on math performance and improvements in behaviors

Parental advocacy may be a protective factor for school dropout

Behavioral and learning challenges in school

None completed high school

All had been homeless

Individualized education with counseling and life support was effective 


\begin{tabular}{|c|c|c|c|}
\hline $\begin{array}{l}\text { Engle (2008) } \\
\text { Quasi-experimental } \\
\text { age \& sex matched }\end{array}$ & $\begin{array}{l}38 \text { children } \\
11-17 \text { years-old } \\
19 \text { FASD } \\
\text { Avg. IQ }-85 \\
19 \text { non-FASD } \\
\text { Avg. IQ }-107\end{array}$ & $\begin{array}{l}\text { Computerized task } \\
\text { with two stimuli of } \\
\text { differing reinforcing } \\
\text { values presented in } \\
120 \text { trials }\end{array}$ & $\begin{array}{l}\text { Both groups } \\
\text { improved } \\
\text { throughout the } \\
\text { task } \\
\text { Non-FASD group } \\
\text { learned reinforc- } \\
\text { ing concept faster }\end{array}$ \\
\hline $\begin{array}{l}\text { Grant, Huggins, } \\
\text { Connor, } \\
\text { Pedersen, } \\
\text { Whitney, \& } \\
\text { Streissguth, } \\
\text { (2004) } \\
\text { Qualitative, pilot } \\
\text { study }\end{array}$ & $\begin{array}{l}19 \text { women } \\
14-36 \text { years-old } \\
\text { FASD (11) Suspected } \\
\text { FASD (8) }\end{array}$ & $\begin{array}{l}12 \text { mo. community } \\
\text { intervention } \\
\text { Providers and advo- } \\
\text { cates trained on } \\
\text { FASD } \\
\text { Trained individuals } \\
\text { provided services } \\
\text { for the participants } \\
\text { in identified areas } \\
\text { of need }\end{array}$ & $\begin{array}{l}\text { Of the women } \\
\text { needing interven- } \\
\text { tions: } \\
5 \text { of } 8 \text { secured } \\
\text { housing } \\
11 \text { of } 16 \text { became } \\
\text { sober from } \\
\text { drugs/alcohol } \\
6 \text { of } 11 \text { began using } \\
\text { contraceptives }\end{array}$ \\
\hline $\begin{array}{l}\text { Kable, Coles, \& } \\
\text { Taddeo (2007) } \\
\text { Randomized con- } \\
\text { trolled study, pre- } \\
\text { post testing }\end{array}$ & $\begin{array}{l}61 \text { children } \\
3-10 \text { years-old } \\
\text { All had FAS }\end{array}$ & $\begin{array}{l}\text { Socio-cognitive } \\
\text { habilitative program } \\
\text { to improve } \\
\text { behavior and math } \\
\text { functioning } \\
\text { Caregivers' training } \\
\text { workshop } \\
6 \text { weeks of tutoring } \\
\text { services for both } \\
\text { children } \& \text { care- } \\
\text { givers in interven- } \\
\text { tion group } \\
\text { Posttest after 4-weeks }\end{array}$ & $\begin{array}{l}\text { Significant knowl- } \\
\text { edge gains in care- } \\
\text { givers } \\
\text { Significant reduc- } \\
\text { tion in problem } \\
\text { behaviors } \\
\text { Math gains in both } \\
\text { groups, but sig- } \\
\text { nificantly higher } \\
\text { gains in interven- } \\
\text { tion group }\end{array}$ \\
\hline $\begin{array}{l}\text { Keil, Paley, } \\
\text { Frankel, \& } \\
\text { O’Connor } \\
\text { (2010) } \\
\text { Randomized } \\
\text { control study }\end{array}$ & $\begin{array}{l}100 \text { children } \\
6-12 \text { years-old } \\
\text { FAS }(11) \text { pFAS } \\
(43) \text { ARND }(46) \\
\text { Verbal IQ > } 70\end{array}$ & $\begin{array}{l}\text { Group 1: CFT } \\
\text { Group 2: Delayed } \\
\text { treatment of CFT } \\
12 \text { weekly sessions } \\
\text { lasting } 90 \text { min. } \\
\text { Pre/Post testing }\end{array}$ & $\begin{array}{l}\text { The CFT group } \\
\text { had significant } \\
\text { decreases in } \\
\text { hostility for peer } \\
\text { group entry, but } \\
\text { not for peer } \\
\text { provocations }\end{array}$ \\
\hline $\begin{array}{l}\text { Kerns, Macsween, } \\
\text { vander Wekken, } \\
\text { \& Gruppuso } \\
(2010)\end{array}$ & $\begin{array}{l}10 \text { children } \\
8-15 \text { years-old } \\
\text { All had FASD Avg. } \\
\text { IQ }-91\end{array}$ & $\begin{array}{l}\text { Computerized } \\
\text { Progressive } \\
\text { Attention Training } \\
\text { program }\end{array}$ & $\begin{array}{l}\text { Children signifi- } \\
\text { cantly improved } \\
\text { on measures of } \\
\text { sustained and } \\
\text { divided attention }\end{array}$ \\
\hline
\end{tabular}


Appendix. (Continued)

Quasi-experimental,
pre-post testing
(no control
group)

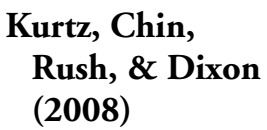

Single-case design: ABCAC \& Multielement designs

\section{2 children}

10-22 months

1 with prenatal alcohol, cocaine, $\&$ heroine exposure; 1 with prenatal heroine exposure

\section{4-11 years-old}

Manji, \&

Andrew (2008)
Randomized controlled trial, Pre-post testing

\section{McGregor (2009)}

Qualitative, Grounded Theory

\author{
16 hours of one-on- \\ one training \\ 3 types of attention
}

Functional assessments determined environmental factors maintaining challenging behaviors

Children were taught to request a preferred item or noncontingently reinforced with ignoring or time-out
Rehearsal training provided for the intervention group Post-test 2 about 10 days after post-test 1
Children significantly improved on meas- ures of distractibility
Children's math and reading fluency improved

Functional assessments effectively determined the reasons for challenging behaviors Instruction on requesting an item decreased challenging behaviors in 2 of 3 conditions

Non-contingent reinforcement with time-out decreased challenging behaviors

The intervention group showed significant improvement in memory performance, especially at post-test 2

No differences observed in the control group

In-depth interviews on the challenges

Self-awareness can aid living with FASD in accepting the supports and accommodations necessary for success

All adults had multiple experiences being fired or resigning from jobs Often others are needed to advocate for their needs 


\begin{tabular}{|c|c|c|c|}
\hline $\begin{array}{l}\text { O'Connor et al. } \\
\text { (2006a) }\end{array}$ & $\begin{array}{l}100 \text { children } \\
6-12 \text { years-old } \\
\text { FAS }(11) \text { pFAS }(43) \\
\text { ARND }(46) \\
\text { Verbal IQ > } 70\end{array}$ & $\begin{array}{l}\text { Group 1: CFT } \\
\text { Group 2: Delayed } \\
\text { treatment of CFT } \\
12 \text { weekly sessions } \\
\text { lasting } 90 \text { min. } \\
\text { Pre/Post testing } \\
3 \text { mo. follow-up }\end{array}$ & $\begin{array}{l}\text { Improved knowledge } \\
\text { of appropriate social } \\
\text { behaviors } \\
\text { Improved social skills } \\
\text { Fewer Problem } \\
\text { behaviors } \\
\text { Outcomes main- } \\
\text { tained at } 3 \text { month } \\
\text { follow-up }\end{array}$ \\
\hline $\begin{array}{l}\text { O'Connor et al. } \\
\text { (2012) } \\
\text { Quasi-experimental } \\
\text { gender, ethnicity, } \\
\text { \& PAE matched }\end{array}$ & $\begin{array}{l}85 \text { children } \\
6-12 \text { years-old } \\
\text { With }(32) \text { and w/o } \\
\text { FASD }(53) \\
\text { Composite IQ > } 70\end{array}$ & $\begin{array}{l}\text { Group 1: CFT } \\
\text { Group 2: } \\
\text { Community stan- } \\
\text { dard of care } \\
12 \text { weekly sessions } \\
\text { lasting } 90 \text { min. } \\
\text { Pre/Post testing }\end{array}$ & $\begin{array}{l}\text { Children in the CFT } \\
\text { group made signif- } \\
\text { cant improvements } \\
\text { in: knowledge of } \\
\text { social skills, self- } \\
\text { concept, and } \\
\text { parent-report of } \\
\text { social skills } \\
\text { CFT was equally } \\
\text { effective for chil- } \\
\text { dren with \& with- } \\
\text { out PAE }\end{array}$ \\
\hline $\begin{array}{l}\text { Padgett, } \\
\text { Strickland, \&x } \\
\text { Coles (2006) }\end{array}$ & $\begin{array}{l}5 \text { children } \\
5-7 \text { years-old } \\
\text { FAS (3) pFAS (2) }\end{array}$ & $\begin{array}{l}\text { Virtual reality com- } \\
\text { puter game (fire } \\
\text { safety) }\end{array}$ & $\begin{array}{l}\text { All } 5 \text { mastered the } \\
\text { computer program } \\
4 \text { generalized all } 3\end{array}$ \\
\hline $\begin{array}{l}\text { Multiple-baseline; } \\
\text { multiple-probe; } \\
\text { pre-post testing }\end{array}$ & Varying IQs $>50$ & $\begin{array}{l}3 \text { levels of instruction } \\
\text { with faded supports } \\
\text { and embedded } \\
\text { reinforcement }\end{array}$ & $\begin{array}{l}\text { steps } \\
3 \text { maintained the } \\
\text { skills after } 1 \text { week }\end{array}$ \\
\hline $\begin{array}{l}\text { Roebuck-Spencer } \\
\text { \& Mattson } \\
\text { (2004) } \\
\text { Quasi-experimental } \\
\text { age matched }\end{array}$ & $\begin{array}{l}69 \text { children } \\
9-16 \text { years-old } \\
\text { FASD }(35) \& \\
\text { non FASD }(34) \\
\text { Avg. IQ }-78 \\
\text { (FASD) - } 105 \\
\text { (non FASD) }\end{array}$ & $\begin{array}{l}\text { Between and within } \\
\text { group comparisons } \\
\text { of children's verbal } \\
\text { learning with and } \\
\text { without the implicit } \\
\text { strategy of semantic } \\
\text { mapping }\end{array}$ & $\begin{array}{l}\text { Children with FASD } \\
\text { learned less infor- } \\
\text { mation, but } \\
\text { retained about the } \\
\text { same information } \\
\text { as children without } \\
\text { FASD } \\
\text { Children with FASD } \\
\text { did not differ from } \\
\text { children without } \\
\text { FASD on learning } \\
\text { and memory using } \\
\text { semantic clustering }\end{array}$ \\
\hline
\end{tabular}


Appendix. (Continued)

\begin{tabular}{|c|c|c|c|}
\hline $\begin{array}{l}\text { Ryan \& Ferguson } \\
\text { (2006) } \\
\text { Qualitative, } \\
\text { 3-year study; con- } \\
\text { textual compari- } \\
\text { son analysis }\end{array}$ & $\begin{array}{l}5 \text { Alaskan students, } \\
\text { their families, \& } \\
\text { professionals } \\
\text { 3-19 years-old } \\
\text { FAS (1) } \\
\text { Alcohol exposed (4) }\end{array}$ & $\begin{array}{l}\text { An evaluation of the } \\
\text { diagnostic team } \\
\text { process of identify- } \\
\text { ing individuals with } \\
\text { FASD \& meeting } \\
\text { student and family } \\
\text { needs }\end{array}$ & $\begin{array}{l}\text { Understanding the } \\
\text { effects of prenatal } \\
\text { alcohol exposure \& } \\
\text { functional abilities } \\
\text { are vital } \\
\text { Experienced teachers } \\
\text { use various methods } \\
\text { to educate students, } \\
\text { but novice teachers } \\
\text { do not differentiate } \\
\text { instruction } \\
\text { Families are frustrated } \\
\text { with the lack of sup- } \\
\text { ports \& services } \\
\text { Families are over- } \\
\text { whelmed with chal- } \\
\text { lenging behaviors }\end{array}$ \\
\hline $\begin{array}{l}\text { Timler, Olswang, } \\
\text { \& Coggins } \\
\text { (2005) } \\
\text { Single case design; } \\
\text { multiple-probe; } \\
\text { pre-post testing }\end{array}$ & $\begin{array}{l}1 \text { child with FASD } \\
9 \text { years-old } \\
2 \text { peers with FASD }\end{array}$ & $\begin{array}{l}\text { Social communication } \\
\text { intervention with } \\
\text { group role play \& } \\
\text { checklist questions } \\
\text { Two one-hour weekly } \\
\text { sessions for the } \\
\text { target child } \\
\text { Three two-hour } \\
\text { weekly sessions for } \\
\text { the group }\end{array}$ & $\begin{array}{l}\text { The specific child } \\
\text { produced more } \\
\text { mental state verbs } \\
\text { and provided alter- } \\
\text { native strategies to } \\
\text { social situations. }\end{array}$ \\
\hline $\begin{array}{l}\text { Randomized con- } \\
\text { trolled study; pre- } \\
\text { post testing }\end{array}$ & $\begin{array}{l}20 \text { children } \\
6-12 \text { years-old } \\
\text { All had FASD }\end{array}$ & $\begin{array}{l}\text { Attention process } \\
\text { training } \\
12 \text { daily } 30 \text { min. } \\
\text { training sessions } \\
\text { After } 3 \text { weeks, post- } \\
\text { test }\end{array}$ & $\begin{array}{l}\text { Significant improve- } \\
\text { ment on sustained } \\
\text { attention \& non- } \\
\text { verbal reasoning, } \\
\text { but not on executive } \\
\text { functioning for chil- } \\
\text { dren in the interven- } \\
\text { tion group }\end{array}$ \\
\hline $\begin{array}{l}\text { Wells, Chasnoff, } \\
\text { Schmidt, } \\
\text { Telford, \& } \\
\text { Schwartz } \\
\text { (2012) } \\
\text { Randomized } \\
\text { controlled study }\end{array}$ & $\begin{array}{l}78 \text { children } \\
6-11 \text { years-old } \\
\text { FAS or ARND } \\
\text { IQs } 45-138\end{array}$ & $\begin{array}{l}\text { The neurocognitive } \\
\text { habilitation cur- } \\
\text { riculum ( } 12 \text { weeks) } \\
\text { Group activity with } \\
\text { core concepts \& } \\
\text { review to promote } \\
\text { memory consolida- } \\
\text { tion }\end{array}$ & $\begin{array}{l}\text { Significant differences } \\
\text { in executive func- } \\
\text { tioning skills and } \\
\text { emotional problem- } \\
\text { solving scores } \\
\text { between treatment } \\
\text { and control group }\end{array}$ \\
\hline
\end{tabular}

Note: FASD = Fetal alcohol spectrum disorder; FAS = Fetal alcohol syndrome; ARND = Alcohol related neurodevelopmental disorder; CFT $=$ Children's Friendship Training 


\section{REFERENCES}

References marked with an asterisk indicate intervention studies that were examined for this research review.

Amendah, D. D., Grosse, S. D., \& Bertrand, J. (2011). Medical expenditures of children in the United States with fetal alcohol syndrome. Neurotoxicity and Teratology, 33, 322-324. doi: 10.1016/j.ntt. 2010.10.008

Aragon, A. S., Coriale, G., Fiorentino, D., Kalberg, W. O., Buckley, D., Gossage, J. P., Ceccanti, M., Mitchell, E. R., \& May, P. A. (2008a). Neuropsychological characteristics of Italian children with fetal alcohol spectrum disorders. Alcoholism: Clinical and Experimental Research, 32, 1909-1919. doi: 10.1111/j.1530-0277.2008.00775.x

Aragon, A. S., Kalberg, W. O., Buckley, D., Barela-Scott, L. M., Tabachnick, B. G., \& May, P. A. (2008b). Neuropsychological study of FASD in a sample of American Indian children: Processing simple versus complex information. Alcoholism: Clinical and Experimental Research, 32, 2136-2148. doi: 10.1111/j.1530-0277.2008.00802.x

Arendt, R. E. \& Farkas, K. J. (2007). Maternal alcohol abuse and fetal alcohol spectrum disorder: A life-span perspective. Alcoholism Treatment Quarterly, 25, 3-20. doi: 10.1300/J020v25n03_02

Bailey, B. N., Delaney-Black, V., Covington, C. Y., Ager, J., Janisse, J., Hannigan, J. H., \& Sokel, R. J. (2004). Prenatal exposure to binge drinking and cognitive and behavioral outcomes at age 7 years. American Journal of Obstetrics and Gynecology, 191, 1037-1043.

Bailey, D. B., Golden, R. N., Roberts, J., \& Ford, A. (2007). Maternal depression and developmental disability: Research critique. Mental Retardation and Developmental Disabilities Research Reviews, 13, 321-329. doi: $10.1002 /$ mrdd. 20172

Bart, O., Agam, T., Weiss, P. L., \& Kizony, R. (2011). Using video-capture virtual reality for children with acquired brain injury. Disability and Rehabilitation, 33, 1579-1586. doi: 10.3109/09638288. 2010.540291

Belcher, H. M. E., Butz, A. M., Wallace, P., Hoon, A., Reinhardt, E., Reeves, S. A., \& Pulsifer, M. B. (2005). Spectrum of early intervention services for children with intrauterine drug exposure. Infants \& Young Children, 18, 2-15.

* Bertrand, J. (2009). Interventions for children with fetal alcohol spectrum disorders (FASD): Overview of findings for five innovative research projects. Research in Developmental Disabilities, 30, 986-1006. doi: 10.1016/j.ridd.2009.02.003 
Bishop, S., Gahagan, S., \& Lord, C. (2007). Re-examining the core features of autism: a comparison of autism spectrum disorder and fetal alcohol spectrum disorder. Journal of Child Psychology and Psychiatry, 48, 1111-1121. doi: 10.1111/j.1469-7610.2007.01782.x

Blackburn, C. \& Whitehurst, T. (2010). Feotal alcohol spectrum disorders (FASD): raising awareness in early years settings, British Journal of Special Education, 37, 122-129. doi: 10.1111/j.1467-8578.2010.00471.x

Brown, C. W., Olson, H. C., \& Croninger, R. G. (2010). Alcohol consumption during pregnancy and infant social, mental, and motor development. Journal of Early Intervention, 32, 110-126. doi: 10.1177/ 1053815110366654

Burd, L. J. (2006). Interventions in FASD: We must do better. Child: Care, Health and Development, 33, 398-400. doi: 10.1111/j.1365-2214. 2006.00696.x

Burd, L., Cotsonas-Hassler, T. M., Martsolf, J. T., \& Kerbeshian, J. (2003). Recognition and management of fetal alcohol syndrome. Neurotoxicology and Teratology, 25, 681-688. doi: 10.1016/ j.ntt.2003.07.020

Burd, L., Klug, M. G., Li, Q., Kerbeshian, J., \& Martsolf, J. T. (2010). Diagnosis of fetal alcohol spectrum disorders: A validity study of the fetal alcohol syndrome checklist. Alcohol, 44, 605-614. doi: 10.1016/ j.alcohol.2009.08.010

Burden, M. J., Andrew, C., Saint-Amour, D., Meintjes, E. M., Molteno, C. D., Hoyme, H. E., ... Jacobson, S. W. (2009). The effects of fetal alcohol syndrome on response execution and inhibition: An event-related potential study. Alcoholism: Clinical and Experimental Research, 33, 1994-2004. doi: 10.1111/j.1530-0277.2009.01038.x

Burgess, D. M. \& Streissguth, A. P. (1992). Fetal alcohol syndrome and fetal alcohol effects: Principles for educators. Phi Delta Kappan, 74, 24-26, 28,30 .

Caley, L. M., Kramer, C., \& Robinson, L. K. (2005). Fetal alcohol spectrum disorder. The Journal of School Nursing, 21, 139-146.

Cannon, M. J., Dominique, Y., O’Leary, L. A., Sniezek, J. E., \& Floyd, R. L. (2012). Characteristics and behaviors of mothers who have a child with fetal alcohol syndrome. Neurotoxicity and Teratology, 34, 90-95. doi: 10.1016/j.ntt.2011.09.010

Caprara, D. L., Nash, K., Greenbaum, R., Rovet, J., \& Koren, G. (2007). Novel approaches to the diagnosis of fetal alcohol spectrum disorder. Neuroscience and Biobehavioral Reviews, 31, 254-260. doi: 10.1016/j.neubiorev.2006.06.015 
* Carpenter, B. (2011). Pedagogically bereft! Improving learning outcomes for children with foetal alcohol spectrum disorders. British Journal of Special Education, 38, 37-43.

Carr, J. L., Agnihotri, S., \& Keightley, M. (2010). Sensory processing and adaptive behavior deficits of children across the fetal alcohol spectrum disorder continuum. Alcoholism: Clinical and Experimental Research, 34(6), 1022-1032. doi: 10.1111/j.1530-0277.2010.01177.x

Centers for Disease Control and Prevention. (October 6, 2010a). Fetal alcohol spectrum disorders: Alcohol use in pregnancy. Retrieved from http://www.cdc.gov/ncbddd/fasd/alcohol-use.html

Centers for Disease Control and Prevention. (October 6, 2010b). Fetal alcohol spectrum disorders: Diagnosis. Retrieved from http://www.cdc.gov/ ncbddd/fasd/diagnosis.html

Centers for Disease Control and Prevention. (September 22, 2011). Fetal alcohol spectrum disorders: Facts about FASD. Retrieved from http://www. cdc.gov/ncbddd/fasd/facts.html

Center for Disabilities. (2008). Fetal alcohol spectrum disorders: Handbook. Sioux Falls, South Dakota: Sanford School of Medicine of the University of South Dakota. Retrieved from http://www.usd.edu/ medical-school/center-for-disabilities/upload/fasdhandbook.pdf

Chang, G. (2004). Screening and brief intervention in prenatal care settings. Alcohol Research and Health, 28, 80-84.

Clark, E., Minnes, P., Lutke, J., \& Ouellette-Kuntz, H. (2008). Caregiver perceptions of the community integration of adults with feotal alcohol spectrum disorder in British Columbia. Journal of Applied Research in Intellectual Disabilities, 21, 446-456. doi: 10.1111/j.1468-3148. 2007.00414.x

Coggins, T. E., Timler, G. R., \& Olswang, L. B. (2007). A state of double jeopardy: Impact of prenatal alcohol exposure and adverse environments on the social communicative abilities of school-age children with fetal alcohol spectrum disorder. Language Speech and Hearing Services in Schools, 38, 117-127.

Coles, C. D. \& Black, M. M. (2006). Introduction to the special issue: Impact of prenatal substance exposure on children's health, development, school performance, and risk behavior. Journal of Pediatric Psychology, 31, 1-4. doi: 10.1093/jpepsy/jsj036

* Coles, C. D., Kable, J. A., \& Taddeo, E. (2009). Math performance and behavior problems in children affected by prenatal alcohol exposure: Intervention and follow-up. Journal of Developmental and Behavioral Pediatrics, 30(1), 7-15. 
Coles, C. D., Platzman, K. A. Raskind-Hood, C. L., Brown, R. T., Falek, A., \& Smith, I. E. (1997). A comparison of children affected by prenatal alcohol exposure and attention deficit, hyperactivity disorder. Alcoholism: Clinical and Experimental Research, 21, 150-161. doi: 10.1111/j.1530-0277.1997.tb03743.x

Coles, C. D., Strickland, D. C., Padgett, L., \& Bellmoff, L. (2007). Games that "work": Using computer games to teach alcohol-affected children about fire and street safety. Research in Developmental Disabilities, 28, 518-530. doi: 10.1016/j.ridd.2006.07.001

Crocker, N., Vaurio, L., Riley, E. P., \& Mattson, S. N. (2011). Comparison of verbal learning and memory in children with heavy prenatal alcohol exposure or attention-deficit/hyperactivity disorder. Alcoholism: Clinical and Experimental Research, 35, 1114-1121. doi: 10.1111/j.1530-0277.2011.01444.x

Davis, K. M., Gagnier, K. R., Moore, T. E., \& Todorow, M. (2013). Cognitive aspects of fetal alcohol spectrum disorder. Wiley Interdisciplinary Reviews: Cognitive Science, 4(1), 81-92. doi: 10.1002/ wcs. 1202

Day, N. L., Helsel, A., Sonon, K., \& Goldschmidt, L. (2013). The association between prenatal alcohol exposure and behavior at 22 years of age. Alcoholism: Clinical and Experimental Research, 37, 1-8. doi: 10.1111/ acer. 12073

Dixon, D. R., Kurtz, P. F., \& Chin, M. D. (2008). A systematic review of challenging behaviors in children exposed prenatally to substances of abuse. Research in Developmental Disabilities, 29, 483-502. doi: 10.1016/j.ridd.2007.05.006

Drotar, D., Aylward, G., \& Beebe, D. (2012). Introduction to the special section: Psychological outcomes of pediatric conditions that affect the central nervous system. Journal of Pediatric Psychology, 37, 707-712. doi: $10.1093 /$ jpepsy/jsso79

Dumaret, A. C., Cousin, M., \& Titran, M. (2010). Two generations of maternal alcohol abuse: Impact on cognitive levels in mothers and their children. Early Child Development and Care, 180, 1311-1321. doi: 10.1080/03004430903040417

* Duquette, C., Stodel, E., Fullarton, S., \& Hagglund, K. (2006). Persistence in high school: Experiences with adolescents and young adults with fetal alcohol spectrum disorder. Journal of Intellectual and Developmental Disability, 31, 219-231. doi: 10.1080/13668250601031930

* Edmunds, K. \& Crichton, S. (2008). Finding ways to teach to students with FASD: A research study. International Journal of Special Education, 23, $54-73$. 
* Engle, J. A. (2008). Reinforcement learning in children and adolescents with fetal alcohol spectrum disorder (FASD) (Doctoral dissertation). Available from ProQuest Dissertations and Theses database.

Ens, C. D., Hanlon-Dearman, A., Millar, M. C., \& Longstaffe, S. (2010). Using Telehealth for assessment of fetal alcohol spectrum disorder: The experience of two Canadian rural and remote communities. Telemedicine and e-Health, 16, 872-877. doi: 10.1089/tmj. 2010.0070

Fagerlund, A., Heikkinen, S., Autti-Ramo, I., Korkman, M., Timonen, M., Kuusi, T., ... Lundbom, N. (2006). Brain metabolic alterations in adolescents and young adults with fetal alcohol spectrum disorders. Alcoholism: Clinical and Experimental Research, 30, 2097-2104. doi: 10.1111/j.1530-0277.2006.00257.x

Fryer, S. L., McGee, C. L., Matt, G. E., Riley, E. P., \& Mattson, S. N. (2007) Evaluation of psychopathological conditions in children with heavy prenatal alcohol exposure. Pediatrics, 119, 733-741.

Goodlett, C. R. (2010). Fetal alcohol spectrum disorders: New perspectives on diagnosis and intervention. Alcohol, 44, 579-582. doi: 10.1016/j.alcohol.2010.10.001

Graham, D. M., Crocker, N., Deweese, B. N., Roesch, S. C., Coles, C. D., Kable, J. A., ... Mattson, S. N. (2012). Prenatal alcohol exposure, attention-deficit/hyperactivity disorder, and sluggish cognitive tempo. Alcoholism: Clinical and Experimental Research, 37, 338-346. doi: 10.1111/j.1530-0277.2012.01886.x

* Grant, T., Huggins, J., Connor, P., Pedersen, J. Y., Whitney, N., \& Streissguth, A. (2004). A pilot community intervention for young women with fetal alcohol spectrum disorders. Community Mental Health Journal, 40, 499-511.

Green, J. H. (2007). Fetal alcohol spectrum disorders: Understanding the effects of prenatal alcohol exposure and supporting students. Journal of School Health, 77, 103-108.

Greenbaum, R. L., Stevens, S. A., Nash, K., Koren, G., \& Rovet, J. (2009). Social cognitive and emotion processing abilities of children with fetal alcohol spectrum disorders: A comparison with attention deficit hyperactivity disorder. Alcoholism: Clinical and Experimental Research, 33, 1656-1670. doi: 10.1111/j.1530-0277.2019.01003.x

Hamilton, D. A., Kodituwakku, P., Sutherland, R. J., \& Savage, D. D. (2003). Children with fetal alcohol syndrome are impaired at place learning but not cued-navigation in a virtual Morris water task. Behavioral Brain Research, 143, 85-94. doi: 10.1016/s0166-4328(03)00028-7

Hanson, J. D., Winberg, A., \& Elliott, A. (2012). Development of a media campaign on fetal alcohol spectrum disorders for Northern Plains 
American Indian communities. Health Promotion Practice, 13, 842-847. doi: 10.1177/1524839911404232

Hope for Women in Recovery Summit. (2005). Understanding and addressing the impact of prenatal alcohol exposure. Retrieved from http://fasdcenter.samhsa.gov/documents/WiR_Proceedings_Raleigh_V2.pdf

Hopkins, R. B., Paradis, J., Roshankar, T., Bowen, J., Tarride, J., Blackhouse, G., ... Longo, C. J. (2008). Universal or targeted screening for fetal alcohol exposure: A cost-effectiveness analysis. Journal of Studies on Alcohol and Drugs, 69, 510-519.

Howell, K. K., Lynch, M. E., Platzman, K. A., Smith, G. H., \& Coles, C. D. (2006). Prenatal alcohol exposure and ability, academic achievement, and school functioning in adolescence: A longitudinal follow-up. Journal of Pediatric Psychology, 31, 116-126. doi: 10.1093/jpepsy/ jsj029

Janzen, L. A., Nanson, J. L., \& Block, G. W. (1995). Neurophysiological evaluation of preschoolers with fetal alcohol syndrome. Neurotoxicity and Teratology, 17, 273-279.

Jirikowic, T., Gelo, J., \& Astley, S. (2010). Children and youth with fetal alcohol spectrum disorders: Summary of intervention recommendations after clinical diagnosis. Intellectual and Developmental Disabilities, 48, 330-344. doi: 10.1352/1934-9556-48.5.330

Johnson, M. K., Hashtroudi, S., \& Lindsay, D. S. (1993). Source monitoring. Psychological Bulletin, 114, 3-28.

Johnston, C., \& Mash, E. J. (1989). A measure of parenting satisfaction and efficacy. Journal of Clinical Child Psychology, 18, 167-175.

* Kable, J. A., Coles, C. D., \& Taddeo, E. (2007). Socio-cognitive habilitation using the math interactive learning experience program for alcoholaffected children. Alcoholism: Clinical and Experimental Research, 31, 1425-1434. doi: 10.1111/j.1530-0277.2007.00431.x

Kalberg, W. O. \& Buckley, D. (2007). FASD: What types of intervention and rehabilitation are useful? Neuroscience and Biobehavioral Reviews, 31, 278-285. doi: 10.1016.j.neubiorev.2006.06.014

* Keil, V., Paley, B., Frankel, F., \& O’Connor, M. J. (2010). Impact of social skills intervention on the hostile attributions of children with prenatal alcohol exposure. Alcoholism: Clinical and Experimental Research, 34, 231-241. doi: 10.1111/j.1530-0277.2009.01086.x

* Kerns, K. A., Macsween, J., vander Wekken, S. V., \& Gruppuso, V. (2010). Investigating the efficacy of an attention training programme in children with feotal alcohol spectrum disorder. Developmental Neurorehabilitation, 13, 413-422. doi: 10.318423.2010. 51142109/ 1751 
Kodituwakku, P. W. (2007). Defining the behavioral phenotype in children with fetal alcohol spectrum disorders: A review. Neuroscience Biobehavioral Reviews, 31, 192-201.

Kodituwakku, P. W. (2009). Neurocognitive profile in children with fetal alcohol spectrum disorders. Developmental Disabilities Research Reviews, 15, 218-224.

Kodituwakku, P. W. (2010). A neurodevelopmental framework for the development of interventions for children with fetal alcohol spectrum disorders. Alcohol, 44, 717-728.

Kodituwakku, P. W., Adnams, C. M., Hay, A., Kitching, A. E., Burger, E., Kalberg, W. O., ... May, P. A. (2006). Letter and category fluency in children with fetal alcohol syndrome from a community in South Africa. Journal of Studies on Alcohol, 67, 502-509.

Kodituwakku, P. W., Handmaker, N. S., Cutler, S. K., Weathersby, E. K., \& Handmaker, S. D. (1995). Specific impairments in self-regulation in children exposed to alcohol prenatally. Alcoholism: Clinical and Experimental Research, 19, 1558-1564.

Kodituwakku, P. W., Kalberg, W. O., \& May, P. A. (2001). The effects of prenatal alcohol exposure on executive functioning. Alcohol Research \& Health: The Journal of the National Institute on Alcohol Abuse and Alcoholism, 25, 192-198.

Kully-Martens, K., Denys, K., Treit, S., Tamana, S., \& Rasmussen, C. (2012). A review of social skills deficits in individuals with fetal alcohol spectrum disorders and prenatal alcohol exposure: Profiles, mechanisms, and interventions. Alcoholism: Clinical and Experimental Research, 36, 568-576. doi: 10.1111/j.1530-0277.2011.01661.x

Kully-Martens, K., Pei, J., Job, J. \& Rasmussen, C., (2012). Source monitoring in children with and without fetal alcohol spectrum disorders (FASD). Journal of Pediatric Psychology, 37, 725-735. doi: 10.1093/jpepsy/jsr123

* Kurtz, P. F., Chin, M. D., Rush, K. S., Dixon, D. R. (2008). Treatment of challenging behavior exhibited by children with prenatal drug exposure. Research in Developmental Disabilities, 29, 582-594. doi: 10.1016/j.ridd.2007.05.007

Kyskan, C. E. \& Moore, T. E. (2005). Global perspectives on fetal alcohol syndrome: Assessing practices, policies, and campaigns in four English-speaking countries. Canadian Psychology, 46(3), 153-165.

* Loomes, C., Rasmussen, C., Pei, J., Manji, S., \& Andrew, G. (2008). The effect of rehearsal training on working memory span of children with fetal alcohol spectrum disorder. Research in Developmental Disabilities, 29(2), 113-124. doi: 10.1016/j.ridd.2007.01.001 
Lotan, M., Yalon-Chamovitz, S., \& Weiss, P. L. (2010). Virtual reality as means to improve physical fitness of individuals at a severe level of intellectual and developmental disability. Research in Developmental Disabilities, 31, 869-874. doi: 10.1016/j.ridd.2010.01.010

Lowe, J., Handmaker, N., \& Aragon, C. (2006). Impact of mother interactive style on infant affect among babies exposed to alcohol in utero. Infant Mental Health Journal, 27, 371-382. doi: 10.1002/imhj.20098

Lupton, C., Burd, L., \& Harwood, R. (2004). Cost of fetal alcohol spectrum disorders. American Journal of Medical Genetics, 127C: 42-50. doi: 10.1002/ajmg.c.30015

Manji, S., Pei, J., Loomes, C., \& Rasmussen, C. (2010). A review of the verbal and visual memory impairments in children with foetal alcohol spectrum disorders. Developmental Neurorehabilitation, 12, 239-247.

Mattson, S. N., Calarco, K. E., \& Lang, A. R. (2006). Focused and shifting attention in children with heavy prenatal alcohol exposure. Neuropsychology, 20, 361-369. doi: 10.1037/0894-4105.20.3.361

Mattson, S. N., Goodman, A. M., Caine, C., Delis, D. C., \& Riley, E. P. (1999). Executive functioning in children with heavy prenatal alcohol exposure. Alcoholism: Clinical and Experimental Research, 23, 1808-1815.

Mattson, S. N. \& Riley, E. P. (2000). Parent ratings of behavior in children with heavy prenatal alcohol exposure and IQ-matched controls. Alcoholism: Clinical and Experimental Research, 24, 226-231.

Mattson, S. N., Riley, E. P., Gramling, L., Delis, D. C., \& Jones, K. L. (1998). Neuropsychological comparison of alcohol-exposed children with or without physical feathers of fetal alcohol syndrome. Neuropsychology, 12, 146-153.

Mattson, S. N. \& Roebuck, T. M. (2002). Acquisition and retention of verbal and nonverbal information in children with heavy prenatal alcohol exposure. Alcoholism: Clinical and Experimental Research, 26, $875-882$.

Mattson, S. N., Roesch, S. C., Glass, L., Deweese, B. N., Coles, C. D., Kable, J. A., ... Riley, E. P. (2013). Further development of a neurobehavioral profile of fetal alcohol spectrum disorders. Alcoholism: Clinical and Experimental Research, 37, 517-528. doi: 10.1111/j.1530-0277. 2012.01952.x

May, P. A., Grossage, J. P., Kalberg, W. O., Robinson, L. K., Buckley, D., Manning, M., \& Hoyme, H. E. (2009). Prevalence and epidemiologic characteristics of FASD from various research methods with an emphasis on recent in-school studies. Developmental Disabilities Research Reviews, 15, 176-192. doi: 10.1002/ddrr.68 
McGee, C. L., Bjorkquist, O. A., Riley, E. P., \& Mattson, S. N. (2009). Impaired language performance in young children with heavy prenatal alcohol exposure. Neurotoxicology and Teratology, 31, 71-75. doi: 10.1016/j.ntt.2008.09.004

* McGregor, D. L. (2009). Never say never: Struggle and determination in the lives of young adults with FASD (Doctoral dissertation). Available from ProQuest Dissertations and Theses database.

Niccols, A. (2007). Fetal alcohol syndrome and the developing socioemotional brain. Brain and Cognition, 65, 135-142. doi: 10.1016/ jbandc.2007.02.009

O'Connor, M. J. \& Kasari, C. (2000). Prenatal alcohol exposure and depressive features in children. Alcoholism: Clinical and Experimental Research, 24, 1084-1092. doi: 0145-6008/00/2407-1084\$03.00/0

* O'Connor, M. J., Frankel, F., Paley, B., Schonfeld, A. M., Carpenter, E., Laugeson, E. A., \& Marquardt, R. (2006). A controlled social skills training for children with fetal alcohol spectrum disorders. Journal of Consulting and Clinical Psychology, 74, 639-648. doi: 10.1016/j.alcohol.2009.10.009

* O'Connor, M. J., Laugeson, E. A., Mogil, C., Lowe, E., Welch-Torres, K., Keil, V., \& Paley, B. (2012). Translation of an evidence-based social skills intervention for children with prenatal alcohol exposure in a community mental health setting. Alcoholism: Clinical and Experimental Research, 36, 141-152. doi: 10.1111/j.1530-0277. 2011.01591.x

O'Connor, M. J. \& Paley, B. (2006). The relationship of prenatal alcohol exposure and the postnatal environment to child depressive symptoms. Journal of Pediatric Psychology, 31, 50-64. doi: 10.1093/jpepsy/jsj021

Olson H. C., Ohlemiller, M. M., O’Connor, M. J., Brown, C. W., Morris, C. A., Damus, K. (2009a). A call to action: Advancing essential services and research on fetal alcohol spectrum disorders. Washington, DC: National Task Force on Fetal Alcohol Syndrome and Fetal Alcohol Effect. Retrieved from http://www.cdc.gov/ncbddd/fasd/documents/calltoaction.pdf

Olson, H. C., Oti, R., Gelo, J., \& Beck, S. (2009b). "Family matters:” Fetal alcohol spectrum disorders and the family. Developmental Disabilities Research Reviews, 15, 235-249. doi: 10.1002/ddrr.65

* Padgett, L. S., Strickland, D., \& Coles, C. D. (2006). Case study: Using a virtual reality computer game to teach fire safety skills to children diagnosed with fetal alcohol syndrome. Journal of Pediatric Psychology, 31, 65-70. doi: 10.1093/jpepsy/jsj030 
Peadon, E., Rhys-Jones, B., Bower, C., \& Elliott, E. J. (2009). Systematic review of interventions for children with fetal alcohol spectrum disorders. BMC Pediatrics, 9, 35-44. doi: 10.1186/1471-2431-9-35

Pei, J., Job, J., Kully-Martens, K., \& Rasmussen, C. (2012). Executive function and memory in children with Fetal Alcohol Spectrum Disorder. Child Neuropsychology, 17, 290-309. doi: 10.1080/ 09297049.2010 .544650

Pei, J., \& Rinaldi, C. (2004). A review of the evolution of diagnostic practices for fetal alcohol spectrum disorder. Developmental Disabilities Bulletin, 32, 125-139.

Poitra, B.A., Marion, S., Dionne, M., Wilkie, E., Dauphinais, P., WilkiePepion, M., ... Burd, L. (2003). A school-based screening program for fetal alcohol syndrome. Neurotoxicology and Teratology, 25, 725-729. doi: 10.1016/j.ntt.2003.07.007

Rasmussen, C. (2005). Executive functioning and working memory in fetal alcohol spectrum disorder. Alcoholism: Clinical and Experimental Research, 29, 1359-1367.

Rasmussen, C. (2006). Mathematics and working memory development in children with fetal alcohol spectrum disorder (Doctoral dissertation). Available from ProQuest Dissertations and Theses database.

Rasmussen, C., Becker, M., McLennan, J., Urichuk, L., \& Andrew, G. (2010). An evaluation of social skills in children with and without prenatal alcohol exposure. Child: Care, Health, and Development, 37, 711-718. doi: 10.1111/j.1365-2214.2010.01152.x

Rasmussen, C. \& Bisanz, J. (2009). Exploring mathematics difficulties in children with fetal alcohol spectrum disorders. Child Development Perspectives, 3, 125-130.

Rasmussen, C., Talwar, V., Loomes, C., \& Andrew, G. (2008). Brief report: Lie-telling in children with fetal alcohol spectrum disorder. Journal of Pediatric Psychology, 33(2), 220-226. doi: 10.1093/jpepsy/jsm069

Riley, E. P. \& McGee, C. L. (2005). Fetal alcohol spectrum disorders: An overview view with emphasis on changes in brain and behavior. Experimental Biology and Medicine, 230, 357-365. Retrieved from http://ebm.rsmjournals.com/content/230/6/357.full

* Roebuck-Spencer, T. M. \& Mattson, S. N. (2004). Implicit strategy affects learning in children with heavy prenatal alcohol exposure. Alcoholism: Clinical and Experimental Research, 28, 1424-1431. doi: 10.1097/01.ALC.0000139826.25247.5B

Rowbottom, L., Merali, N., \& Pei, J. (2010). Interventions for non-biological caregivers of children with fetal alcohol spectrum disorder. Developmental Disabilities Bulletin, 38, 35-54. 
* Ryan, S. \& Ferguson, D. L. (2006). On, yet under, the radar: Students with fetal alcohol syndrome disorder. Exceptional Children, 72, 363-379.

Schonfeld, A. M., Paley, B., Frankel, F., \& O'Connor, M. J. (2006). Executive functioning predicts social skills following prenatal alcohol exposure. Child Neuropsychology, 12, 439-452. doi: 10.1080/ 09297040600611338

Simmons, R. W., Thomas, J. D., Levy, S. S., \& Riley, E. P. (2006). Motor response selection in children with fetal alcohol spectrum disorders. Neurotoxicology and Teratology, 28, 278-285. doi: 10.1016/ j.ntt.2006.01.008

Skinner, D. \& Weisner, T. S. (2007). Sociocultural studies of families of children with intellectual disabilities. Mental Retardation and Developmental Disabilities, 13, 302-312. doi: 10.1002/mrdd. 20170

Skogerbø, Å., Kesmodel, U., Wimberley, T., Støvring, H., Bertrand, J., Landrø, N., \& Mortensen, E. (2012). The effects of low to moderate alcohol consumption and binge drinking in early pregnancy on executive function in 5-year-old children. BJOG: An International Journal of Obstetrics and Gynecology, 119, 1201-1210. doi: 10.1111/ j.1471-0528.2012.03397.x

Sood, B., Delaney-Black, V., Covington, C., Nordstrom-Klee, B., Ager, J., Templin, T., ... Sokol, R. J. (2001). Prenatal alcohol exposure and childhood behavior at age 6 to 7 years: I. Dose-response effect. Pediatrics, 27, 108-134.

Spohr, H., Willms, J., \& Steinhausen, H. (2007). Fetal alcohol spectrum disorders in young adulthood. The Journal of Pediatrics, 150, 175-179. doi: 10.1016/j.peds.2006.11.044

Stephen, J. M., Kodituwakku, P. W., Kodituwakku, E. L., Romero, L., Peters, A. M., Sharadamma, N. M., ... Coffman, B. A. (2012). Delays in auditory processing identified in preschool children with FASD. Alcoholism: Clinical \& Experimental Research, 36, 1720-1727. doi: 10.1111/j.1530-0277.2012.01769.x

Streissguth, A. P., Barr, H. M., Kogan, J., \& Bookstein, F. L. (1996). Understanding the occurrence of secondary disabilities in clients with fetal alcohol syndrome and fetal alcohol effects: Final report to the Centers for Disease Control. Seattle, WA: University of Washington, Fetal Alcohol and Drug Unit.

Streissguth, A. P. (1997). Fetal alcohol syndrome: A guide to families and communities. Baltimore, MD: Guilford Press.

Streissguth, A. P., Bookstein, F. L., Barr, H. M., Sampson, P. D., O’Malley, K., \& Young, J. K. (2004). Risk factors for adverse life outcomes in fetal 
alcohol syndrome and fetal alcohol effects. Developmental and Behavioral Pediatrics, 25, 228-238. doi: 0196-206X/00/2504-0228

Strickland, D. C., McAllister, D., Coles, C. D., \& Osborne, S. (2007). An evolution of virtual reality training designs for children with autism and fetal alcohol spectrum disorders. Topics in Language Disorders, 27, 226-241.

Substance Abuse and Mental Health Services Administration. (2011). Results from the 2010 National Survey on Drug Use and Health: Summary of National Findings, NSDUH Series H-41, HHS Publication No. (SMA) 11-4658. Rockville, MD: Substance Abuse and Mental Health Services Administration.

* Timler, G. R., Olswang, L. B., \& Coggins, T. E. (2005). "Do I know what I need to do?" A social communication intervention for children with complex clinical profiles. Language, Speech, and Hearing Services in Schools, 36, 73-85.

* Vernescu, R. (2008). Sustained attention training in children with fetal alcohol spectrum disorder (Doctoral dissertation). Available from ProQuest Dissertations and Theses database.

Ware, A. L., O’Brien, J. W., Crocker, N., Deweese, B. N., Roesch, S. C., Coles, C. D., ... Mattson, S. N. (2012). The effects of prenatal alcohol exposure and attention-deficit/hyperactivity disorder on psychopathology and behavior. Alcoholism: Clinical and Experimental Research, 37, 507-516. doi: 10.1111/j.1530-0277.2012.01886.x

Watson, E., Finkelstein, N., Gurewich, D., \& Morse, B. (2011). The feasibility of screening for fetal alcohol spectrum disorders risk in early intervention settings: A pilot study of systems change. Infants \& Young Children, 24, 193-206. doi: 10.1097/IYC0b013e31820d97c9

* Wells, A. M., Chasnoff, I. J., Schmidt, C. A., Telford, E., \& Schwartz, L. D. (2012). Neurocognitive habilitation therapy for children with fetal alcohol spectrum disorders: An adaptation of the Alert Program. American Journal of Occupational Therapy, 66, 24-34. doi: 10.5014/ajot.111.002691

Whaley, S. E., O'Connor, M. J., \& Gunderson, B. (2001). Comparison of the adaptive functioning of children prenatally exposed to alcohol to a nonexposed clinical sample. Alcoholism: Clinical and Experimental Research, 25(7), 1018-1024.

Willford, J. A., Richardson, G. A., Leech, S. L., \& Day, N. L. (2004). Verbal and visuospatial learning and memory function in children with moderate prenatal alcohol exposure. Alcoholism: Clinical \& Experimental Research, 28(3), 497-507. 
Williams, B. F. \& Howard, V. R. (1994). Fetal alcohol syndrome: Developmental characteristics and directions for further research. Education and Treatment of Children, 17, 86-97.

Wozniak, J. R., Mueller, B. A., Muetzel, R. L., Bell, C. J., Hoecker, H. L., Nelson, M. L., Chang, P. N., \& Lim, K. O. (2011). Inter-hemispheric functional connectivity disruption in children with prenatal alcohol exposure. Alcoholism: Clinical and Experimental Research, 35, 849-861. doi: 10.1111/j.1530-0277.2010.01415.x

Yuen, E. K., Herbert, J. D., Forman, E. M., Goetter, E. M., Comer, R., \& Bradley, J. C. (2013). Treatment of social anxiety disorder using online virtual environments in second life. Behavior Therapy, 44, 51-61.

Zelner, I., Shor, S., Lynn, H., Roukema, H., Lum, L., Eisinga, K., \& Koren, G. (2012). Neonatal screening for prenatal alcohol exposure: Assessment of voluntary maternal participation in an open meconium screening program. Alcohol, 46, 269-276. doi: 10.1016/j.alcohol.2011.09.029 


\section{APPENDIX B}

References with digital object identifier (DOI) numbers added:

References marked with an asterisk indicate intervention studies that were examined for this research review.

Amendah, D. D., Grosse, S. D., \& Bertrand, J. (2011). Medical expenditures of children in the United States with fetal alcohol syndrome. Neurotoxicity and Teratology, 33, 322-324. http://dx.doi.org/10.1016/j.ntt.2010.10.008

Aragon, A. S., Coriale, G., Fiorentino, D., Kalberg, W. O., Buckley, D., Gossage, J. P., Ceccanti, M., Mitchell, E. R., \& May, P. A. (2008a). Neuropsychological characteristics of Italian children with fetal alcohol spectrum disorders. Alcoholism: Clinical and Experimental Research, 32, 1909-1919. http://dx.doi.org/10.1111/j.1530-0277.2008.00775.x

Aragon, A. S., Kalberg, W. O., Buckley, D., Barela-Scott, L. M., Tabachnick, B. G., \& May, P. A. (2008b). Neuropsychological study of FASD in a sample of American Indian children: Processing simple versus complex information. Alcoholism: Clinical and Experimental Research, 32, 2136-2148. http://dx.doi.org/10.1111/j.1530-0277.2008.00802.x

Arendt, R. E. \& Farkas, K. J. (2007). Maternal alcohol abuse and fetal alcohol spectrum disorder: A life-span perspective. Alcoholism Treatment Quarterly, 25, 3-20. http://dx.doi.org/10.1300/J020v25n03_02

Bailey, B. N., Delaney-Black, V., Covington, C. Y., Ager, J., Janisse, J., Hannigan, J. H., \& Sokel, R. J. (2004). Prenatal exposure to binge drinking and cognitive and behavioral outcomes at age 7 years. American Journal of Obstetrics and Gynecology, 191, 10371043. http://dx.doi.org/10.1016/j.ajog.2004.05.048

Bailey, D. B., Golden, R. N., Roberts, J., \& Ford, A. (2007). Maternal depression and developmental disability: Research critique. Mental Retardation and Developmental Disabilities Research Reviews, 13, 321-329. http://dx.doi.org/10.1002/mrdd.20172

Bart, O., Agam, T., Weiss, P. L., \& Kizony, R. (2011). Using video-capture virtual reality for children with acquired brain injury. Disability and Rehabilitation, 33, 1579-1586. http://dx.doi.org/10.3109/09638288. 2010.540291

Belcher, H. M. E., Butz, A. M., Wallace, P., Hoon, A., Reinhardt, E., Reeves, S. A., \& Pulsifer, M. B. (2005). Spectrum of early intervention services for children with intrauterine drug exposure. Infants \& Young Children, 18, 2-15. http://dx.doi.org/10.1097/00001163$\underline{200501000-00002}$

* Bertrand, J. (2009). Interventions for children with fetal alcohol spectrum disorders (FASD): Overview of findings for five innovative research projects. Research in Developmental Disabilities, 30, 986-1006. http://dx.doi.org/10.1016/j.ridd.2009.02.003 
Bishop, S., Gahagan, S., \& Lord, C. (2007). Re-examining the core features of autism: A comparison of autism spectrum disorder and fetal alcohol spectrum disorder. Journal of Child Psychology and Psychiatry, 48, 1111-1121. http://dx.doi.org/10.1111/j.14697610.2007.01782.x

Blackburn, C. \& Whitehurst, T. (2010). Feotal alcohol spectrum disorders (FASD): Raising awareness in early years settings. British Journal of Special Education, 37, 122-129. http://dx.doi.org/10.1111/j.1467-8578.2010.00471.x

Brown, C. W., Olson, H. C., \& Croninger, R. G. (2010). Alcohol consumption during pregnancy and infant social, mental, and motor development. Journal of Early Intervention, 32, 110-126. http://dx.doi.org/10.1177/1053815110366654

Burd, L. J. (2006). Interventions in FASD: We must do better. Child: Care, Health and Development, 33, 398-400. http://dx.doi.org/10.1111/j.1365-2214.2006.00696.x

Burd, L., Cotsonas-Hassler, T. M., Martsolf, J. T., \& Kerbeshian, J. (2003). Recognition and management of fetal alcohol syndrome. Neurotoxicology and Teratology, 25, 681-688. http://dx.doi.org/10.1016/j.ntt.2003.07.020

Burd, L., Klug, M. G., Li, Q., Kerbeshian, J., \& Martsolf, J. T. (2010). Diagnosis of fetal alcohol spectrum disorders: A validity study of the fetal alcohol syndrome checklist. Alcohol, 44, 605-614. http://dx.doi.org/10.1016/j.alcohol.2009.08.010

Burden, M. J., Andrew, C., Saint-Amour, D., Meintjes, E. M., Molteno, C. D., Hoyme, H. E., ... Jacobson, S. W. (2009). The effects of fetal alcohol syndrome on response execution and inhibition: An event-related potential study. Alcoholism: Clinical and Experimental Research, 33, 1994-2004. http://dx.doi.org/10.1111/j.1530-0277.2009.01038.x

Burgess, D. M. \& Streissguth, A. P. (1992). Fetal alcohol syndrome and fetal alcohol effects: Principles for educators. Phi Delta Kappan, 74, 24-26, 28, 30.

Caley, L. M., Kramer, C., \& Robinson, L. K. (2005). Fetal alcohol spectrum disorder. The Journal of School Nursing, 21, 139-146. http://dx.doi.org/10.1177/10598405050210030301

Cannon, M. J., Dominique, Y., O’Leary, L. A., Sniezek, J. E., \& Floyd, R. L. (2012). Characteristics and behaviors of mothers who have a child with fetal alcohol syndrome. Neurotoxicity and Teratology, 34, 90-95. http://dx.doi.org/10.1016/j.ntt.2011.09.010

Caprara, D. L., Nash, K., Greenbaum, R., Rovet, J., \& Koren, G. (2007). Novel approaches to the diagnosis of fetal alcohol spectrum disorder. Neuroscience and Biobehavioral Reviews, 31, 254-260. http://dx.doi.org/10.1016/j.neubiorev.2006.06.015 
* Carpenter, B. (2011). Pedagogically bereft! Improving learning outcomes for children with foetal alcohol spectrum disorders. British Journal of Special Education, 38, 37-43. http://dx.doi.org/10.1111/j.1467-8578.2011.00495.x

Carr, J. L., Agnihotri, S., \& Keightley, M. (2010). Sensory processing and adaptive behavior deficits of children across the fetal alcohol spectrum disorder continuum. Alcoholism: Clinical and Experimental Research, 34(6), 1022-1032. http://dx.doi.org/10.1111/j.1530$\underline{0277.2010 .01177 . x}$

Centers for Disease Control and Prevention. (October 6, 2010a). Fetal alcohol spectrum disorders: Alcohol use in pregnancy. Retrieved from http://www.cdc.gov/ncbddd/fasd/alcohol-use.html

Centers for Disease Control and Prevention. (October 6, 2010b). Fetal alcohol spectrum disorders: Diagnosis. Retrieved from http://www.cdc.gov/ncbddd/fasd/diagnosis.html

Centers for Disease Control and Prevention. (September 22, 2011). Fetal alcohol spectrum disorders: Facts about FASD. Retrieved from http://www.cdc.gov/ncbddd/fasd/facts.html

Center for Disabilities. (2008). Fetal alcohol spectrum disorders: Handbook. Sioux Falls, South Dakota: Sanford School of Medicine of the University of South Dakota. Retrieved from http://www.usd.edu/medical-school/center-for-disabilities/upload/fasdhandbook.pdf

Chang, G. (2004). Screening and brief intervention in prenatal care settings. Alcohol Research and Health, 28, 80-84.

Clark, E., Minnes, P., Lutke, J., \& Ouellette-Kuntz, H. (2008). Caregiver perceptions of the community integration of adults with feotal alcohol spectrum disorder in British Columbia. Journal of Applied Research in Intellectual Disabilities, 21, 446-456. http://dx.doi.org/10.1111/j.1468-3148.2007.00414.x

Coggins, T. E., Timler, G. R., \& Olswang, L. B. (2007). A state of double jeopardy: Impact of prenatal alcohol exposure and adverse environments on the social communicative abilities of school-age children with fetal alcohol spectrum disorder. Language Speech and Hearing Services in Schools, 38, 117-127. http://dx.doi.org/10.1044/0161$\underline{1461(2007 / 012)}$

Coles, C. D. \& Black, M. M. (2006). Introduction to the special issue: Impact of prenatal substance exposure on children's health, development, school performance, and risk behavior. Journal of Pediatric Psychology, 31, 1-4. http://dx.doi.org/10.1093/jpepsy/jsj036

* Coles, C. D., Kable, J. A., \& Taddeo, E. (2009). Math performance and behavior problems in children affected by prenatal alcohol exposure: Intervention and follow-up. Journal of Developmental and Behavioral Pediatrics, 30(1), 7-15. http://dx.doi.org/10.1097/DBP.0b013e3181966780 
Coles, C. D., Platzman, K. A. Raskind-Hood, C. L., Brown, R. T., Falek, A., \& Smith, I. E. (1997). A comparison of children affected by prenatal alcohol exposure and attention deficit, hyperactivity disorder. Alcoholism: Clinical and Experimental Research, 21, 150-161. http://dx.doi.org/10.1111/j.1530-0277.1997.tb03743.x

Coles, C. D., Strickland, D. C., Padgett, L., \& Bellmoff, L. (2007). Games that "work": Using computer games to teach alcohol-affected children about fire and street safety. Research in Developmental Disabilities, 28, 518-530. http://dx.doi.org/10.1016/i.ridd.2006.07.001

Crocker, N., Vaurio, L., Riley, E. P., \& Mattson, S. N. (2011). Comparison of verbal learning and memory in children with heavy prenatal alcohol exposure or attentiondeficit/hyperactivity disorder. Alcoholism: Clinical and Experimental Research, 35, 1114-1121. http://dx.doi.org/10.1111/j.1530-0277.2011.01444.x

Davis, K. M., Gagnier, K. R., Moore, T. E., \& Todorow, M. (2013). Cognitive aspects of fetal alcohol spectrum disorder. Wiley Interdisciplinary Reviews: Cognitive Science, 4(1), 8192. http://dx.doi.org/10.1002/wcs.1202

Day, N. L., Helsel, A., Sonon, K., \& Goldschmidt, L. (2013). The association between prenatal alcohol exposure and behavior at 22 years of age. Alcoholism: Clinical and Experimental Research, 37, 1-8. http://dx.doi.org/10.1111/acer.12073

Dixon, D. R., Kurtz, P. F., \& Chin, M. D. (2008). A systematic review of challenging behaviors in children exposed prenatally to substances of abuse. Research in Developmental Disabilities, 29, 483-502. http://dx.doi.org/10.1016/j.ridd.2007.05.006

Drotar, D., Aylward, G., \& Beebe, D. (2012). Introduction to the special section: Psychological outcomes of pediatric conditions that affect the central nervous system. Journal of Pediatric Psychology, 37, 707-712. http://dx.doi.org/10.1093/jpepsy/jsso79

Dumaret, A. C., Cousin, M., \& Titran, M. (2010). Two generations of maternal alcohol abuse: Impact on cognitive levels in mothers and their children. Early Child Development and Care, 180, 1311-1321. http://dx.doi.org/10.1016/jbandc.2007.02.00910.1080/03004430903040417

* Duquette, C., Stodel, E., Fullarton, S., \& Hagglund, K. (2006). Persistence in high school: Experiences with adolescents and young adults with fetal alcohol spectrum disorder. Journal of Intellectual and Developmental Disability, 31, 219-231. http://dx.doi.org/10.1080/13668250601031930

* Edmunds, K. \& Crichton, S. (2008). Finding ways to teach to students with FASD: A research study. International Journal of Special Education, 23, 54-73. 
* Engle, J. A. (2008). Reinforcement learning in children and adolescents with fetal alcohol spectrum disorder (FASD) (Doctoral dissertation). Available from ProQuest Dissertations and Theses database.

Ens, C. D., Hanlon-Dearman, A., Millar, M. C., \& Longstaffe, S. (2010). Using Telehealth for assessment of fetal alcohol spectrum disorder: The experience of two Canadian rural and remote communities. Telemedicine and e-Health, 16, 872-877. http://dx.doi.org/10.1089/tmj. 2010.0070

Fagerlund, A., Heikkinen, S., Autti-Ramo, I., Korkman, M., Timonen, M., Kuusi, T., ... Lundbom, N. (2006). Brain metabolic alterations in adolescents and young adults with fetal alcohol spectrum disorders. Alcoholism: Clinical and Experimental Research, 30, 2097-2104. http://dx.doi.org/10.1111/j.1530-0277.2006.00257.x

Fryer, S. L., McGee, C. L., Matt, G. E., Riley, E. P., \& Mattson, S. N. (2007) Evaluation of psychopathological conditions in children with heavy prenatal alcohol exposure. Pediatrics, 119, 733-741. http://dx.doi.org/10.1542/peds.2006-1606

Goodlett, C. R. (2010). Fetal alcohol spectrum disorders: New perspectives on diagnosis and intervention. Alcohol, 44, 579-582. http://dx.doi.org/10.1016/j.alcohol.2010.10.001

Graham, D. M., Crocker, N., Deweese, B. N., Roesch, S. C., Coles, C. D., Kable, J. A., ... Mattson, S. N. (2012). Prenatal alcohol exposure, attention-deficit/hyperactivity disorder, and sluggish cognitive tempo. Alcoholism: Clinical and Experimental Research, 37, 338346. http://dx.doi.org/10.1111/j.1530-0277.2012.01886.x

* Grant, T., Huggins, J., Connor, P., Pedersen, J. Y., Whitney, N., \& Streissguth, A. (2004). A pilot community intervention for young women with fetal alcohol spectrum disorders. Community Mental Health Journal, 40, 499-511. http://dx.doi.org/10.1007/s10597-004$\underline{6124-6}$

Green, J. H. (2007). Fetal alcohol spectrum disorders: Understanding the effects of prenatal alcohol exposure and supporting students. Journal of School Health, 77, 103-108. http://dx.doi.org/10.1111/j.1746-1561.2007.00178.x

Greenbaum, R. L., Stevens, S. A., Nash, K., Koren, G., \& Rovet, J. (2009). Social cognitive and emotion processing abilities of children with fetal alcohol spectrum disorders: A comparison with attention deficit hyperactivity disorder. Alcoholism: Clinical and Experimental Research, 33, 1656-1670. http://dx.doi.org/10.1111/j.1530$\underline{0277.2019 .01003 . x}$

Hamilton, D. A., Kodituwakku, P., Sutherland, R. J., \& Savage, D. D. (2003). Children with fetal alcohol syndrome are impaired at place learning but not cued-navigation in a virtual Morris water task. Behavioral Brain Research, 143, 85-94. http://dx.doi.org/10.1016/s0166-4328(03)00028-7 
Hanson, J. D., Winberg, A., \& Elliott, A. (2012). Development of a media campaign on fetal alcohol spectrum disorders for Northern Plains American Indian communities. Health Promotion Practice, 13, 842-847. http://dx.doi.org/10.1177/1524839911404232

Hope for Women in Recovery Summit. (2005). Understanding and addressing the impact of prenatal alcohol exposure. Retrieved from http://fasdcenter.samhsa.gov/documents/WiR_Proceedings_Raleigh_V2.pdf

Hopkins, R. B., Paradis, J., Roshankar, T., Bowen, J., Tarride, J., Blackhouse, G., ... Longo, C. J. (2008). Universal or targeted screening for fetal alcohol exposure: A cost-effectiveness analysis. Journal of Studies on Alcohol and Drugs, 69, 510-519.

Howell, K. K., Lynch, M. E., Platzman, K. A., Smith, G. H., \& Coles, C. D. (2006). Prenatal alcohol exposure and ability, academic achievement, and school functioning in adolescence: A longitudinal follow-up. Journal of Pediatric Psychology, 31, 116-126. http://dx.doi.org/10.1093/jpepsy/jsj029

Janzen, L. A., Nanson, J. L., \& Block, G. W. (1995). Neurophysiological evaluation of preschoolers with fetal alcohol syndrome. Neurotoxicity and Teratology, 17, 273-279. http://dx.doi.org/10.1016/0892-0362(94)00063-J

Jirikowic, T., Gelo, J., \& Astley, S. (2010). Children and youth with fetal alcohol spectrum disorders: Summary of intervention recommendations after clinical diagnosis. Intellectual and Developmental Disabilities, 48, 330-344. http://dx.doi.org/10.1352/1934-9556$\underline{48.5 .330}$

Johnson, M. K., Hashtroudi, S., \& Lindsay, D. S. (1993). Source monitoring. Psychological Bulletin, 114, 3-28. http://dx.doi.org/10.1037/0033-2909.114.1.3

Johnston, C., \& Mash, E. J. (1989). A measure of parenting satisfaction and efficacy. Journal of Clinical Child Psychology, 18, 167-175. http://dx.doi.org/10.1207/s15374424jccp1802_8

* Kable, J. A., Coles, C. D., \& Taddeo, E. (2007). Socio-cognitive habilitation using the math interactive learning experience program for alcohol affected children. Alcoholism: Clinical and Experimental Research, 31, 1425-1434. http://dx.doi.org/10.1111/j.1530$\underline{0277.2007 .00431 . x}$

Kalberg, W. O. \& Buckley, D. (2007). FASD: What types of intervention and rehabilitation are useful? Neuroscience and Biobehavioral Reviews, 31, 278-285. http://dx.doi.org/10.1016.j.neubiorev.2006.06.014

* Keil, V., Paley, B., Frankel, F., \& O’Connor, M. J. (2010). Impact of social skills intervention on the hostile attributions of children with prenatal alcohol exposure. Alcoholism: Clinical and Experimental Research, 34, 231-241. http://dx.doi.org/10.1111/j.1530$\underline{0277.2009 .01086 . x}$ 
* Kerns, K. A., Macsween, J., vander Wekken, S. V., \& Gruppuso, V. (2010). Investigating the efficacy of an attention training programme in children with feotal alcohol spectrum disorder. Developmental Neurorehabilitation, 13, 413-422. http://dx.doi.org/10.318423.2010. 51142109/1751

Kodituwakku, P. W. (2007). Defining the behavioral phenotype in children with fetal alcohol spectrum disorders: A review. Neuroscience Biobehavioral Reviews, 31, 192-201. http://dx.doi.org/10.1016/j.neubiorev.2006.06.020

Kodituwakku, P. W. (2009). Neurocognitive profile in children with fetal alcohol spectrum disorders. Developmental Disabilities Research Reviews, 15, 218-224. http://dx.doi.org/10.1002/ddrr.73

Kodituwakku, P. W. (2010). A neurodevelopmental framework for the development of interventions for children with fetal alcohol spectrum disorders. Alcohol, 44, 717-728. http://dx.doi.org/10.1016/j.alcohol.2009.10.009

Kodituwakku, P. W., Adnams, C. M., Hay, A., Kitching, A. E., Burger, E., Kalberg, W. O., ... May, P. A. (2006). Letter and category fluency in children with fetal alcohol syndrome from a community in South Africa. Journal of Studies on Alcohol, 67, 502-509.

Kodituwakku, P. W., Handmaker, N. S., Cutler, S. K., Weathersby, E. K., \& Handmaker, S. D. (1995). Specific impairments in self-regulation in children exposed to alcohol prenatally. Alcoholism: Clinical and Experimental Research, 19, 1558-1564. http://dx.doi.org/10.1111/j.1530-0277.1995.tb01024.x

Kodituwakku, P. W., Kalberg, W. O., \& May, P. A. (2001). The effects of prenatal alcohol exposure on executive functioning. Alcohol Research \& Health: The Journal of the National Institute on Alcohol Abuse and Alcoholism, 25, 192-198.

Kully-Martens, K., Denys, K., Treit, S., Tamana, S., \& Rasmussen, C. (2012). A review of social skills deficits in individuals with fetal alcohol spectrum disorders and prenatal alcohol exposure: Profiles, mechanisms, and interventions. Alcoholism: Clinical and Experimental Research, 36, 568-576. http://dx.doi.org/10.1111/j.1530$\underline{0277.2011 .01661 . x}$

Kully-Martens, K., Pei, J., Job, J. \& Rasmussen, C., (2012). Source monitoring in children with and without fetal alcohol spectrum disorders (FASD). Journal of Pediatric Psychology, 37, 725-735. http://dx.doi.org/10.1093/jpepsy/jsr123

* Kurtz, P. F., Chin, M. D., Rush, K. S., Dixon, D. R. (2008). Treatment of challenging behavior exhibited by children with prenatal drug exposure. Research in Developmental Disabilities, 29, 582-594. http://dx.doi.org/10.1016/j.ridd.2007.05.007 
Kyskan, C. E. \& Moore, T. E. (2005). Global perspectives on fetal alcohol syndrome: Assessing practices, policies, and campaigns in four English-speaking countries. Canadian Psychology, 46(3), 153-165. http://dx.doi.org/10.1037/h0087018

* Loomes, C., Rasmussen, C., Pei, J., Manji, S., \& Andrew, G. (2008). The effect of rehearsal training on working memory span of children with fetal alcohol spectrum disorder. Research in Developmental Disabilities, 29(2), 113-124. http://dx.doi.org/10.1016/j.ridd.2007.01.001

Lotan, M., Yalon-Chamovitz, S., \& Weiss, P. L. (2010). Virtual reality as means to improve physical fitness of individuals at a severe level of intellectual and developmental disability. Research in Developmental Disabilities, 31, 869-874. http://dx.doi.org/10.1016/j.ridd.2010.01.010

Lowe, J., Handmaker, N., \& Aragon, C. (2006). Impact of mother interactive style on infant affect among babies exposed to alcohol in utero. Infant Mental Health Journal, 27, 371382. http://dx.doi.org/10.1002/imhj.20098

Lupton, C., Burd, L., \& Harwood, R. (2004). Cost of fetal alcohol spectrum disorders. American Journal of Medical Genetics, 127C(1), 42-50. http://dx.doi.org/10.1002/ajmg.c.30015

Manji, S., Pei, J., Loomes, C., \& Rasmussen, C. (2010). A review of the verbal and visual memory impairments in children with foetal alcohol spectrum disorders. Developmental Neurorehabilitation, 12, 239-247. http://dx.doi.org/10.1080/17518420902980118

Mattson, S. N., Calarco, K. E., \& Lang, A. R. (2006). Focused and shifting attention in children with heavy prenatal alcohol exposure. Neuropsychology, 20, 361-369. http://dx.doi.org/10.1037/0894-4105.20.3.361

Mattson, S. N., Goodman, A. M., Caine, C., Delis, D. C., \& Riley, E. P. (1999). Executive functioning in children with heavy prenatal alcohol exposure. Alcoholism: Clinical and Experimental Research, 23, 1808-1815. http://dx.doi.org/10.1111/j.15300277.1999.tb04077.x

Mattson, S. N. \& Riley, E. P. (2000). Parent ratings of behavior in children with heavy prenatal alcohol exposure and IQ-matched controls. Alcoholism: Clinical and Experimental Research, 24, 226-231. http://dx.doi.org/10.1111/j.1530-0277.2000.tb04595.x

Mattson, S. N., Riley, E. P., Gramling, L., Delis, D. C., \& Jones, K. L. (1998). Neuropsychological comparison of alcohol-exposed children with or without physical feathers of fetal alcohol syndrome. Neuropsychology, 12, 146-153. http://dx.doi.org/10.1037/0894-4105.12.1.146

Mattson, S. N. \& Roebuck, T. M. (2002). Acquisition and retention of verbal and nonverbal information in children with heavy prenatal alcohol exposure. Alcoholism: Clinical and 
Experimental Research, 26, 875-882. http://dx.doi.org/10.1111/j.1530$\underline{0277.2002 . t b 02617 . \mathrm{x}}$

Mattson, S. N., Roesch, S. C., Glass, L., Deweese, B. N., Coles, C. D., Kable, J. A., ... Riley, E. P. (2013). Further development of a neurobehavioral profile of fetal alcohol spectrum disorders. Alcoholism: Clinical and Experimental Research, 37, 517-528. http://dx.doi.org/10.1111/j.1530-0277.2012.01952.x

May, P. A., Grossage, J. P., Kalberg, W. O., Robinson, L. K., Buckley, D., Manning, M., \& Hoyme, H. E. (2009). Prevalence and epidemiologic characteristics of FASD from various research methods with an emphasis on recent in-school studies. Developmental Disabilities Research Reviews, 15, 176-192. http://dx.doi.org/10.1002/ddrr.68

McGee, C. L., Bjorkquist, O. A., Riley, E. P., \& Mattson, S. N. (2009). Impaired language performance in young children with heavy prenatal alcohol exposure. Neurotoxicology and Teratology, 31, 71-75. http://dx.doi.org/10.1016/j.ntt.2008.09.004

* McGregor, D. L. (2009). Never say never: Struggle and determination in the lives of young adults with FASD (Doctoral dissertation). Available from ProQuest Dissertations and Theses database.

Niccols, A. (2007). Fetal alcohol syndrome and the developing socioemotional brain. Brain and Cognition, 65, 135-142. http://dx.doi.org/10.1016/jbandc.2007.02.009

O'Connor, M. J. \& Kasari, C. (2000). Prenatal alcohol exposure and depressive features in children. Alcoholism: Clinical and Experimental Research, 24, 1084-1092. http://dx.doi.org/0145-6008/00/2407-1084\$03.00/0

* O’Connor, M. J., Frankel, F., Paley, B., Schonfeld, A. M., Carpenter, E., Laugeson, E. A., \& Marquardt, R. (2006). A controlled social skills training for children with fetal alcohol spectrum disorders. Journal of Consulting and Clinical Psychology, 74, 639-648. http://dx.doi.org/10.1016/j.alcohol.2009.10.009

* O’Connor, M. J., Laugeson, E. A., Mogil, C., Lowe, E., Welch-Torres, K., Keil, V., \& Paley, B. (2012). Translation of an evidence-based social skills intervention for children with prenatal alcohol exposure in a community mental health setting. Alcoholism: Clinical and Experimental Research, 36, 141-152. http://dx.doi.org/10.1111/j.1530$\underline{0277.2011 .01591 . x}$

O'Connor, M. J. \& Paley, B. (2006). The relationship of prenatal alcohol exposure and the postnatal environment to child depressive symptoms. Journal of Pediatric Psychology, 31, 50-64. http://dx.doi.org/10.1093/jpepsy/jsj021

Olson H. C., Ohlemiller, M. M., O'Connor, M. J., Brown, C. W., Morris, C. A., Damus, K. (2009a). A call to action: Advancing essential services and research on fetal alcohol spectrum disorders. Washington, DC. 
National Task Force on Fetal Alcohol Syndrome and Fetal Alcohol Effect. Retrieved from http://www.cdc.gov/ncbddd/fasd/documents/calltoaction.pdf

Olson, H. C., Oti, R., Gelo, J., \& Beck, S. (2009b). "Family matters:” Fetal alcohol spectrum disorders and the family. Developmental Disabilities Research Reviews, 15, 235-249. http://dx.doi.org/10.1002/ddrr.65

* Padgett, L. S., Strickland, D., \& Coles, C. D. (2006). Case study: Using a virtual reality computer game to teach fire safety skills to children diagnosed with fetal alcohol syndrome. Journal of Pediatric Psychology, 31, 65-70. http://dx.doi.org/10.1093/jpepsy/jsj030

Peadon, E., Rhys-Jones, B., Bower, C., \& Elliott, E. J. (2009). Systematic review of interventions for children with fetal alcohol spectrum disorders. BMC Pediatrics, 9, 3544. http://dx.doi.org/10.1186/1471-2431-9-35

Pei, J., Job, J., Kully-Martens, K., \& Rasmussen, C. (2012). Executive function and memory in children with Fetal Alcohol Spectrum Disorder. Child Neuropsychology, 17, 290-309. http://dx.doi.org/10.1080/09297049.2010.544650

Pei, J., \& Rinaldi, C. (2004). A review of the evolution of diagnostic practices for fetal alcohol spectrum disorder. Developmental Disabilities Bulletin, 32, 125-139.

Poitra, B.A., Marion, S., Dionne, M., Wilkie, E., Dauphinais, P., Wilkie-Pepion, M., ... Burd, L. (2003). A school-based screening program for fetal alcohol syndrome. Neurotoxicology and Teratology, 25, 725-729. http://dx.doi.org/10.1016/j.ntt.2003.07.007

Rasmussen, C. (2005). Executive functioning and working memory in fetal alcohol spectrum disorder. Alcoholism: Clinical and Experimental Research, 29, 1359-1367. http://dx.doi.org/10.1097/01.alc.0000175040.91007.d0

Rasmussen, C. (2006). Mathematics and working memory development in children with fetal alcohol spectrum disorder (Doctoral dissertation). Available from ProQuest Dissertations and Theses database.

Rasmussen, C., Becker, M., McLennan, J., Urichuk, L., \& Andrew, G. (2010). An evaluation of social skills in children with and without prenatal alcohol exposure. Child: Care, Health, and Development, 37, 711-718. http://dx.doi.org/10.1111/j.1365-2214.2010.01152.x

Rasmussen, C. \& Bisanz, J. (2009). Exploring mathematics difficulties in children with fetal alcohol spectrum disorders. Child Development Perspectives, 3, 125-130. http://dx.doi.org/10.1111/j.1750-8606.2009.00091.x 
Rasmussen, C., Talwar, V., Loomes, C., \& Andrew, G. (2008). Brief report: Lie-telling in children with fetal alcohol spectrum disorder. Journal of Pediatric Psychology, 33(2), 220-226. http://dx.doi.org/10.1093/jpepsy/jsm069

Riley, E. P. \& McGee, C. L. (2005). Fetal alcohol spectrum disorders: An overview with emphasis on changes in brain and behavior. Experimental Biology and Medicine, 230, 357-365. Retrieved from http://ebm.rsmjournals.com/content/230/6/357.full

* Roebuck-Spencer, T. M. \& Mattson, S. N. (2004). Implicit strategy affects learning in children with heavy prenatal alcohol exposure. Alcoholism: Clinical and Experimental Research, 28, 1424-1431. http://dx.doi.org/10.1097/01.ALC.0000139826.25247.5B

Rowbottom, L., Merali, N., \& Pei, J. (2010). Interventions for non-biological caregivers of children with fetal alcohol spectrum disorder. Developmental Disabilities Bulletin, 38, $35-54$.

* Ryan, S. \& Ferguson, D. L. (2006). On, yet under, the radar: Students with fetal alcohol syndrome disorder. Exceptional Children, 72, 363-379. http://dx.doi.org/10.1177/001440290607200307

Schonfeld, A. M., Paley, B., Frankel, F., \& O’Connor, M. J. (2006). Executive functioning predicts social skills following prenatal alcohol exposure. Child Neuropsychology, 12, 439-452. http://dx.doi.org/10.1080/09297040600611338

Simmons, R. W., Thomas, J. D., Levy, S. S., \& Riley, E. P. (2006). Motor response selection in children with fetal alcohol spectrum disorders. Neurotoxicology and Teratology, 28, 278285. http://dx.doi.org/10.1016/j.ntt.2006.01.008

Skinner, D. \& Weisner, T. S. (2007). Sociocultural studies of families of children with intellectual disabilities. Mental Retardation and Developmental Disabilities, 13, 302312. http://dx.doi.org/10.1002/mrdd.20170

Skogerbø, Å., Kesmodel, U., Wimberley, T., Støvring, H., Bertrand, J., Landrø, N., \& Mortensen, E. (2012). The effects of low to moderate alcohol consumption and binge drinking in early pregnancy on executive function in 5-year-old children. BJOG: An International Journal of Obstetrics and Gynecology, 119, 1201-1210. http://dx.doi.org/10.1111/j.1471-0528.2012.03397.x

Sood, B., Delaney-Black, V., Covington, C., Nordstrom-Klee, B., Ager, J., Templin, T., ... Sokol, R. J. (2001). Prenatal alcohol exposure and childhood behavior at age 6 to 7 years: I. Dose-response effect. Pediatrics, 27, 108-134.

Spohr, H., Willms, J., \& Steinhausen, H. (2007). Fetal alcohol spectrum disorders in young adulthood. The Journal of Pediatrics, 150, 175-179. http://dx.doi.org/10.1016/j.peds.2006.11.044 
Stephen, J. M., Kodituwakku, P. W., Kodituwakku, E. L., Romero, L., Peters, A. M., Sharadamma, N. M., ... Coffman, B. A. (2012). Delays in auditory processing identified in preschool children with FASD. Alcoholism: Clinical \& Experimental Research, 36, 1720-1727. http://dx.doi.org/10.1111/j.1530-0277.2012.01769.x

Streissguth, A. P., Barr, H. M., Kogan, J., \& Bookstein, F. L. (1996). Understanding the occurrence of secondary disabilities in clients with fetal alcohol syndrome and fetal alcohol effects: Final report to the Centers for Disease Control. Seattle, WA: University of Washington, Fetal Alcohol and Drug Unit.

Streissguth, A. P. (1997). Fetal alcohol syndrome: A guide to families and communities. Baltimore, MD: Guilford Press.

Streissguth, A. P., Bookstein, F. L., Barr, H. M., Sampson, P. D., O’Malley, K., \& Young, J. K. (2004). Risk factors for adverse life outcomes in fetal alcohol syndrome and fetal alcohol effects. Developmental and Behavioral Pediatrics, 25, 228-238. http://dx.doi.org/0196$\underline{206 X / 00 / 2504-0228}$

Strickland, D. C., McAllister, D., Coles, C. D., \& Osborne, S. (2007). An evolution of virtual reality training designs for children with autism and fetal alcohol spectrum disorders. Topics in Language Disorders, 27, 226-241. http://dx.doi.org/10.1097/01.TLD.0000285357.95426.72

Substance Abuse and Mental Health Services Administration. (2011). Results from the 2010 National Survey on Drug Use and Health: Summary of National Findings, NSDUH Series H-41, HHS Publication No. (SMA) 11-4658. Rockville, MD: Substance Abuse and Mental Health Services Administration.

* Timler, G. R., Olswang, L. B., \& Coggins, T. E. (2005). “Do I know what I need to do?” A social communication intervention for children with complex clinical profiles. Language, Speech, and Hearing Services in Schools, 36, 73-85. http://dx.doi.org/10.1044/0161$\underline{1461(2005 / 007)}$

* Vernescu, R. (2008). Sustained attention training in children with fetal alcohol spectrum disorder (Doctoral dissertation). Available from ProQuest Dissertations and Theses database.

Ware, A. L., O’Brien, J. W., Crocker, N., Deweese, B. N., Roesch, S. C., Coles, C. D., ... Mattson, S. N. (2012). The effects of prenatal alcohol exposure and attentiondeficit/hyperactivity disorder on psychopathology and behavior. Alcoholism: Clinical and Experimental Research, 37, 507-516. http://dx.doi.org/10.1111/j.1530$\underline{\text { 0277.2012.01886.x }}$

Watson, E., Finkelstein, N., Gurewich, D., \& Morse, B. (2011). The feasibility of screening for fetal alcohol spectrum disorders risk in early intervention settings: A pilot study of 
systems change. Infants \& Young Children, 24, 193-206.

http://dx.doi.org/10.1097/IYC0b013e31820d97c9

* Wells, A. M., Chasnoff, I. J., Schmidt, C. A., Telford, E., \& Schwartz, L. D. (2012).

Neurocognitive habilitation therapy for children with fetal alcohol spectrum disorders:

An adaptation of the Alert Program. American Journal of Occupational Therapy, 66, 2434. http://dx.doi.org/10.1016/jbandc.2007.02.00910.5014/ajot.111.002691

Whaley, S. E., O’Connor, M. J., \& Gunderson, B. (2001). Comparison of the adaptive functioning of children prenatally exposed to alcohol to a nonexposed clinical sample. Alcoholism: Clinical and Experimental Research, 25(7), 1018-1024. http://dx.doi.org/10.1111/j.1530-0277.2001.tb02311.x

Willford, J. A., Richardson, G. A., Leech, S. L., \& Day, N. L. (2004). Verbal and visuospatial learning and memory function in children with moderate prenatal alcohol exposure. Alcoholism: Clinical \& Experimental Research, 28(3), 497-507. http://dx.doi.org/10.1097/01.ALC.0000117868.97486.2D

Williams, B. F. \& Howard, V. R. (1994). Fetal alcohol syndrome: Developmental characteristics and directions for further research. Education and Treatment of Children, 17, 86-97.

Wozniak, J. R., Mueller, B. A., Muetzel, R. L., Bell, C. J., Hoecker, H. L., Nelson, M. L., Chang, P. N., \& Lim, K. O. (2011). Inter-hemispheric functional connectivity disruption in children with prenatal alcohol exposure. Alcoholism: Clinical and Experimental Research, 35, 849-861. http://dx.doi.org/10.1111/j.1530-0277.2010.01415.x

Yuen, E. K., Herbert, J. D., Forman, E. M., Goetter, E. M., Comer, R., \& Bradley, J. C. (2013). Treatment of social anxiety disorder using online virtual environments in second life. Behavior Therapy, 44, 51-61. http://dx.doi.org/10.1016/j.beth.2012.06.001

Zelner, I., Shor, S., Lynn, H., Roukema, H., Lum, L., Eisinga, K., \& Koren, G. (2012). Neonatal screening for prenatal alcohol exposure: Assessment of voluntary maternal participation in an open meconium screening program. Alcohol, 46, 269-276. http://dx.doi.org/10.1016/j.alcohol.2011.09.029 